\title{
ENHANCING MICROFIBRILLATED CELLULOSE \\ REINFORCING EFFICIENCY IN EPOXY COMPOSITES BY \\ GRAPHENE OXIDE CROSSLINKING
}

by

\section{YUNYANG QIANG}

Submitted in partial fulfillment of the requirements

for the degree of Master of Science

Thesis Advisor: Prof. Ica Manas-Zloczower

Department of Macromolecular Science and Engineering

CASE WESTERN RESERVE UNIVERSITY

August 2019 


\title{
CASE WESTERN RESERVE UNIVERSITY SCHOOL OF GRADUATE STUDIES
}

\author{
We hereby approve the thesis/dissertation of \\ Yunyang Qiang
}

Candidate for the degree of Master of Science *.

\author{
Committee Chair \\ Ica Manas-Zloczower
}

Committee Member

David Schiraldi

\author{
Committee Member \\ Joao Maia
}

Date of Defense

04/30/2019

*We also certify that written approval has been obtained for any proprietary material contained therein. 


\section{Table of Contents}

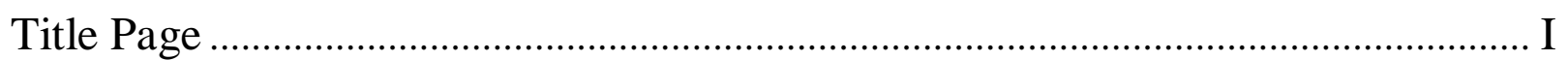

Committee Approval Sheet ...........................................................................

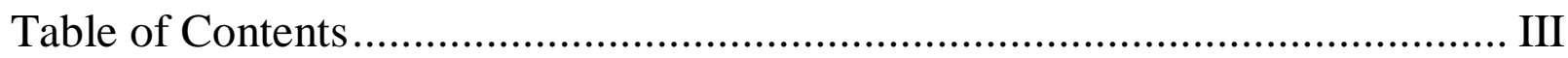

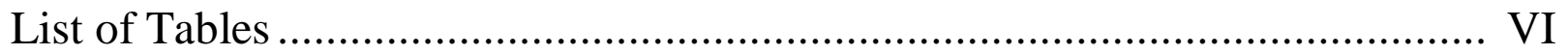

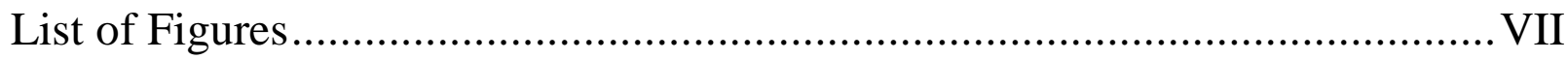

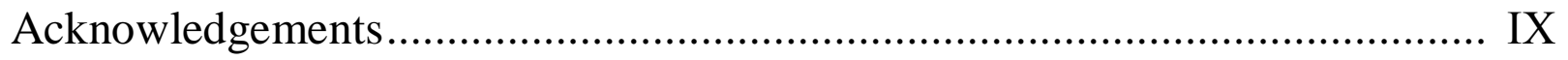

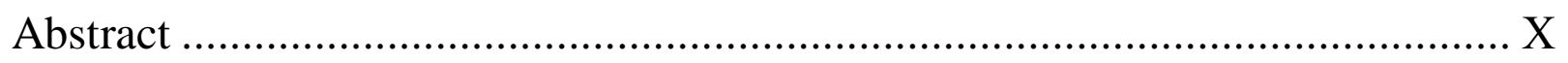

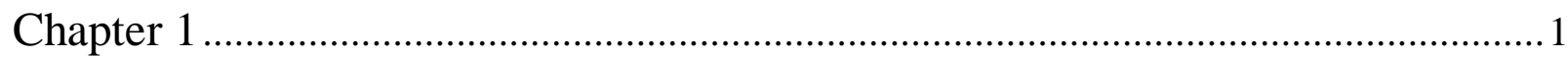

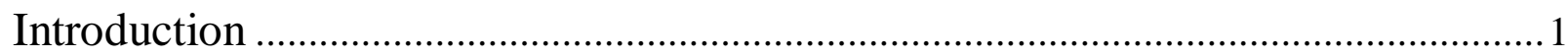

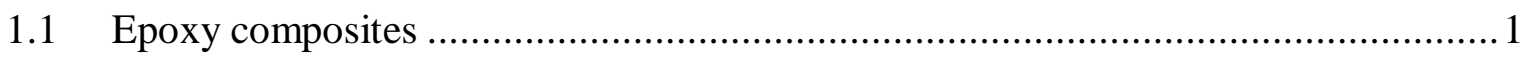

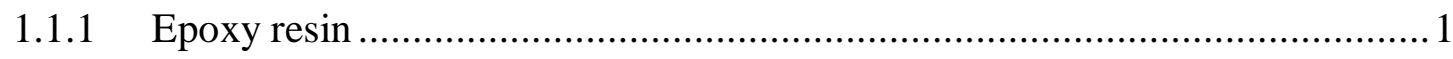

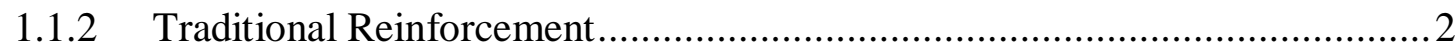

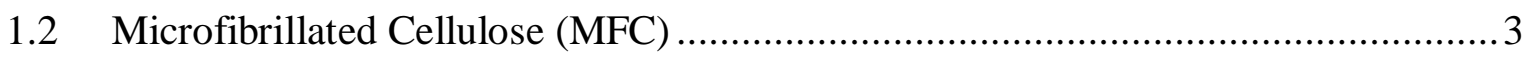

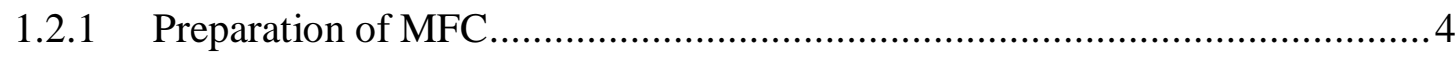

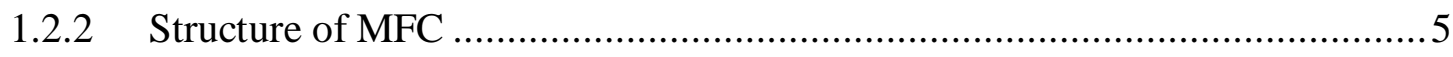

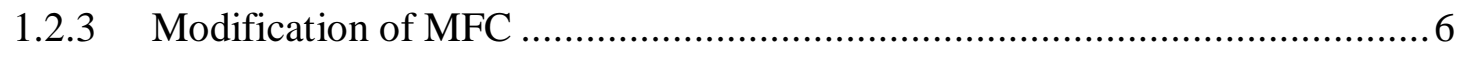




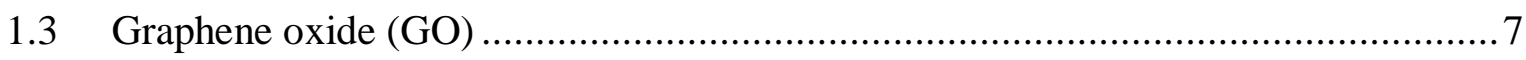

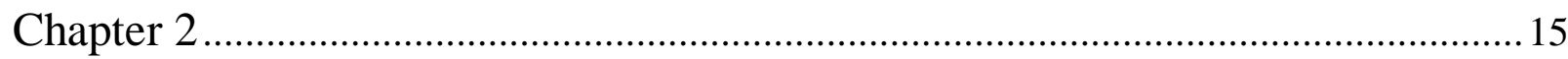

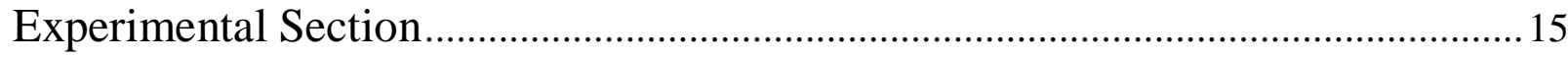

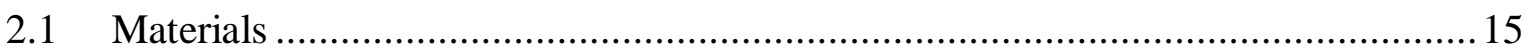

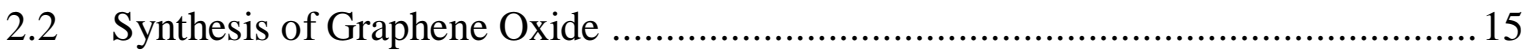

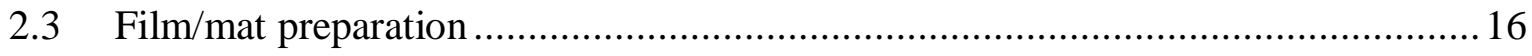

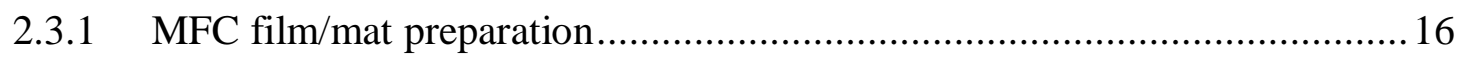

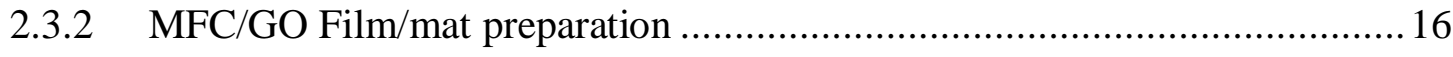

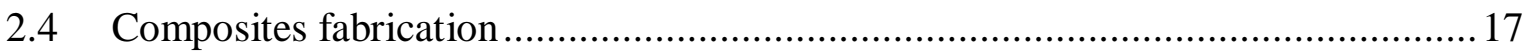

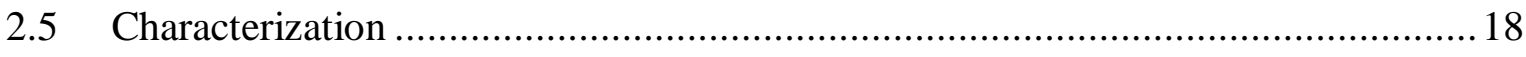

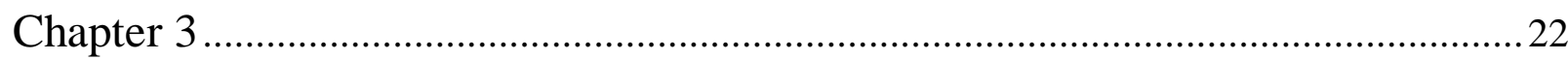

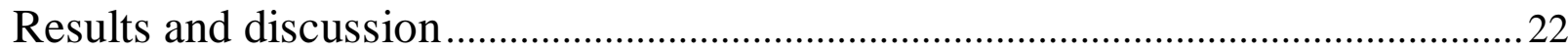

3.1 Optimization of the composites fabrication process .........................................22

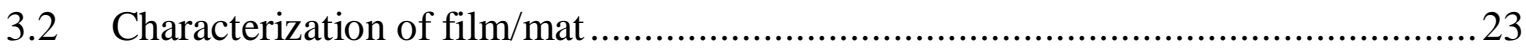

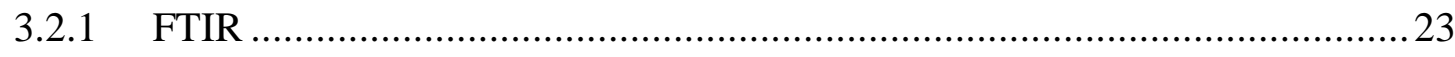

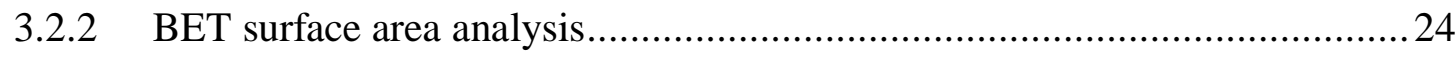

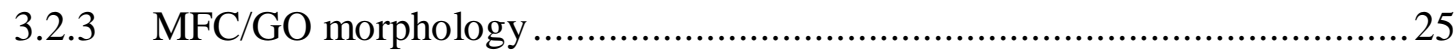

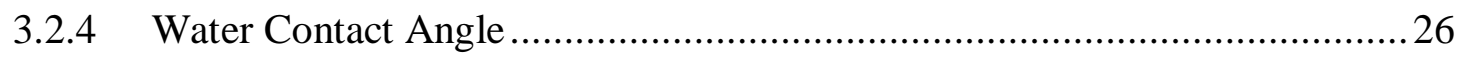




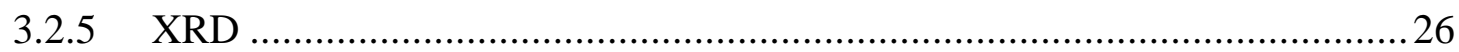

3.3 Characterization of Composites ................................................................. 27

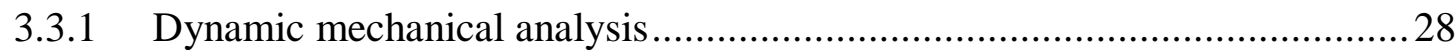

3.3.3 Thermal stability .................................................................. 30

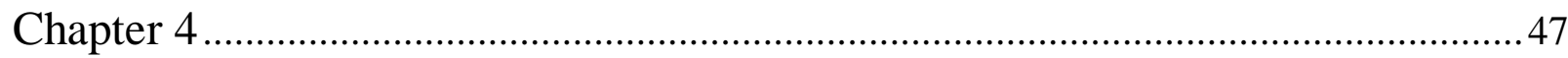

Conclusion and future works................................................................. 47

4.1 Conclusion ................................................................................. 47

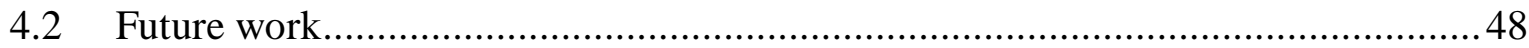

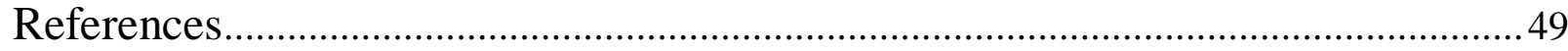




\section{List of Tables}

Table 3.1 Porosity of MFC samples prepared with different drying methods....................... 31

Table 3.2 Weight ratio and volume ratio of each components in MFC/epoxy composites ......32

Table 3.2 Storage Modulus normalized by relative density ........................................... 33 


\section{List of Figures}

Figure 1.1 Chemical structure of DGEBA

Figure 1.2 Chemical structure of Polyetheramines 10

Figure 1.3 Curing mechanism of amine and epoxy

Figure 1.4 Chemical structure of cellulose

Figure 1.5 Cross-sectional structure model (Modified Frey-Wyssling model) of a cellulose nanofiber composed of six elementary fibrils

Figure 1.6 Structure model (Lerf-Klinowski model) of Graphene oxide 14

Figure 2.1 Crosslinking reaction between hydroxyl groups and epichlorohydrin 21

Figure 3.1 SEM images of air-dried MFC samples and freeze-dried MFC samples 34

Figure 3.2 Storage modulus of MFC/epoxy composites with different volume ratio of air content 35

Figure 3.3 (a) ATR-FTIR of GO, NaOH treated GO and ECH modified GO; (b) FTIR of Crosslinked GO/MFC film and Non-crosslinked GO/MFC film .36

Figure 3.4 (a) Specific surface area of Non-crosslinked and crosslinked MFC/GO mats; (b) Pore size distribution analyzed by $\mathrm{BJH}$ method of Non-crosslinked MFC/GO mat, Crosslinked MFC/GO mat 37

Figure 3.5 (a) SEM image of crosslinked $2 \mathrm{wt} \%-\mathrm{GO} / \mathrm{MFC}$ mat (b) SEM image of noncrosslinked GO/MFC mat 
Figure 3.6 Water contact angle of neat MFC (top), crosslinked MFC (bottom left), crosslinked $2 \mathrm{wt} \%-\mathrm{GO} / \mathrm{MFC}$ (bottom right) 39

Figure 3.7 XRD for Non-crosslinked MFC and Crosslinked MFC mat 40

Figure 3.8 Tensile test for Non-crosslinked MFC film (MFC), crosslinked MFC film (MFC-x) and crosslinked MFC/GO film with $1 \mathrm{wt} \%, 2 \mathrm{wt} \%$, 10wt $\%$ GO loading

Figure 3.9 Storage modulus of non-crosslinked MFC/epoxy composites 42

Figure 3.10 (a) Storage Modulus for crosslinked MFC/GO epoxy composites (b) Storage modulus comparison between MFC/epoxy, Glass fiber/epoxy and crosslinked 2wt\% GO/MFC composites, (c) Glass transition temperature for crosslinked MFC/epoxy composites. 43

Figure 3.11 Storage modulus of GO/MFC epoxy composites with 0.4 wt. $\%, 1$ wt. $\%$ and 2 wt. $\%$ GO. 44

Figure 3.12(a) Tensile modulus of epoxy composites with 15 vol \% MFC, (b) Tensile Strength, (c) Stain at break 45

Figure 3.13 Thermal degradation peak for neat epoxy, glass fiber /epoxy, MFC/epoxy and MFC/GO epoxy composites consists of 15 vol. \% MFC with different amounts of GO crosslinking in wt.\% 46 


\section{Acknowledgement}

Foremost, I would like to express my sincere gratitude to my advisor, Professor Ica Manas-Zloczower for her patient guidance, enthusiastic encouragement and useful critiques of this research work.

I would like to thank all of the members in our group for inspiring me to push through and see my Masters completed. It was a pleasure working with all of you. I would like to especially thank Ammar Patel for being my mentor and offering me continuous help and suggestions throughout this project.

I would also like to thank Weidmann Fiber Technology for kindly providing the Microfibrillated Cellulose used in this project.

Finally, I must express my very profound gratitude to my parents for providing me with unfailing support and continuous encouragement throughout my years of study. 


\title{
Enhancing Microfibrillated Cellulose Reinforcing efficiency in Epoxy \\ Composites by Graphene Oxide Crosslinking
}

\author{
Abstract \\ by \\ YUNYANG QIANG
}

Microfibrillated Cellulose (MFC) has the potential to be used as an alternative reinforcement to glass fibers. However, glass fiber reinforced epoxy composites at usual operating temperatures (below $\mathrm{Tg}$ ) are still superior to MFC infused epoxy composites.

In this work, MFC with variable amounts of Graphene Oxide (GO) crosslinking were prepared using epichlorohydrin (ECH). Crosslinked MFC/GO epoxy composites with constant fiber content and different GO loadings were fabricated by impregnation of the freeze-dried crosslinked MFC/GO mat with the epoxy/hardener mixture followed by compression molding. Composites with 15 vol. \% MFC and $2 \mathrm{wt} \%$ GO crosslinking, have a storage modulus in the glassy state $\left(40^{\circ} \mathrm{C}\right)$ of $6.5 \mathrm{GPa}$, which surpasses the storage modulus of glass fiber/epoxy composite with similar fiber volume content $(6.0 \mathrm{GPa}$ at $40{ }^{\circ} \mathrm{C}$ ). Thus, with a small amount of GO crosslinking. MFC was shown to possess superior modulus and lower weight when compared to glass fiber composites at similar fiber volume content. 


\section{Chapter 1}

\section{Introduction}

\subsection{Epoxy composites}

\subsubsection{Epoxy resin}

Composites combine the superior properties of polymer matrix and fillers and can achieve far better performances than those of the constituent materials acting alone. In composites, fillers carry the loading while the polymer matrix holds them together, acting as load transfer medium. Mechanical properties of composites are highly influenced by the interfacial adhesion of fillermatrix and the strength of fillers, as failure usually occurs through interface debonding or breakdown of fillers. Epoxy resins are often the polymer matrix of choice for advanced composites materials due to their thermal stability, solvent resistance and excellent mechanical properties.

Epoxy resins, also known as polyepoxides, is thermosetting resins. To fabricate epoxy materials, the epoxy resin needs to be mixed with an appropriate harder to form a curing system. Bisphenol A diglycidyl ether (DGEBA), as one of the most common glycidyl epoxy resin, is synthesized by reacting epichlorohydrin with bisphenol-A. ${ }^{1}$ Structure of DGEBA is shown in Figure 1.1. Other main types of epoxy include cycloaliphatic epoxy, trifunctional epoxy, 
tetrafunctional epoxy, navolac epoxy etc. Besides, bio-based epoxy became of great interest in the past few years and has revealed its potential as a replacement for traditional petroleum-based epoxy like DGEBA in the future.

The curing kinetics and mechanical properties of epoxy material are influenced by the chemical structure of the hardener used. ${ }^{2}$ Polyetheramines are representative for the amine-type hardener. Its structure is shown in Figure 1.2. The curing reaction of epoxy resin with aminetype hardener has been demonstrated in Figure 1.3.

\subsubsection{Traditional Reinforcement}

Traditional reinforcement commercially used in epoxy composites are glass fibers and carbon fibers. The use of these fibers can largely improve the mechanical properties of composites. Choi et al. ${ }^{3}$ used vapor grown carbon nanofibers to reinforce epoxy with different viscosities. With $20 \mathrm{wt} \%$ carbon fiber content, the storage modulus of the epoxy composites increased by 14 and 27 times for the high and low viscosity epoxy composites, respectively, by comparison with neat epoxy. Hameed et al. ${ }^{4}$ used E-glass fiber to reinforce a modified epoxy. The room temperature storage modulus of the matrix is enhanced by more than $460 \%$ upon the addition of 50 vol. \% glass fiber.

While these results are impressive, these fibers are either non-biodegradable or too expensive and both can result in a significant increase in the weight/density of the composites. 


\subsection{Microfibrillated Cellulose (MFC)}

In recent years, with the growing need for high strength and biodegradable composites with low cost and low density, there is huge drive for the development and utilization of biobased reinforcement alternatives to conventional fiber reinforcement.

Researchers have reported an extensive list of cellulosic materials that could potentially reinforce the polymeric matrices, including nanocellulose materials such as Microfibrillated Cellulose (MFC) or Cellulose Nanofiber $(\mathrm{CNC}),{ }^{5}$ Bacterial Cellulose (BC), ${ }^{6}$ Cellulose Nanocrystals (CNC), ${ }^{7,8}$ Cellulose Nanowhisker ${ }^{9,10}$ and some micro-sized fillers including wood flour ${ }^{11,12}$ and plant derived fibers etc. ${ }^{13-17}$ Micro-sized fillers usually contain large amounts of non-cellulosic components like lignin and hemicellulose, ${ }^{18}$ which result in relative low mechanical properties of these fibers. When isolating nanocellulose from their plant derived raw material, ${ }^{19-21}$ however, non-cellulosic components as well as some amorphous regions of cellulose are removed leading to an incredibly high crystallinity and mechanical property.

Among all the nanocellulose materials, MFC and BC are preferred due to their high aspect ratio. The diameter of these nano-sized cellulose fibers is around tens of nanometers and their length could be up to few hundreds microns, ${ }^{22,23}$ leading to a percolated fiber network than can be achieved via filtration ${ }^{24}$. Hence, composites with high volume fraction of fibers can be prepared solvent-free by impregnation of the porous fiber mat with epoxy or other resins. To date, to culture bacterial cellulose is still time-consuming. ${ }^{25}$ The production of MFC by 
fibrillation of wood pulp is a faster process and relatively cheap. Besides, the cost of MFC could be much lower if the fabrication process was optimized, since wood is the most abundant and cheap biomaterial available on earth. Compared to glass fibers, the density of microfibrillated cellulose (MFC) is much lower $\left(<1.6 \mathrm{~g} / \mathrm{cm} 3,{ }^{23}\right.$ versus $2.5 \sim 2.6 \mathrm{~g} / \mathrm{cm} 3$ for glass fibers) while possessing a relatively high modulus (up to $150 \mathrm{GPa}$ ). ${ }^{26}$ These excellent properties make MFC an ideal alternative for glass fibers.

\subsubsection{Preparation of MFC}

Cellulose microfibrils, as the principal constituent of plant cell wall, are entangled and randomly arranged in a matrix consisting of lignins, pectin and hemicellulose. ${ }^{27,28} \mathrm{MFC}$, composed of these elementary fibrils, could be prepared from natural resources including wood pulp and agricultural residues with a mechanical treatment consisting of refining and homogenization processes. ${ }^{29}$ The homogenization process is usually conducted at high pressure and repeated several times to ensure an appropriate degree of fibrillation. As a result, the high energy consumption during the mechanical treatment becomes a major challenge in MFC preparation. To facilitate the fibrillation and reduce the energy consumption, a chemical or enzymatic treatment is required prior to the mechanical fibrillation process. ${ }^{30,31}$

Alkaline treatment and TEMPO-mediated oxidation are the most commonly used chemical treatment methods. Alkaline treatment dissolves the pectin and hemicellulose and disrupts the linkage between cellulose microfibrils and lignins, thus extracting intact cellulose microfibrils. ${ }^{32}$ The treatment condition needs to be carefully controlled to avoid the degradation 
and hydrolysis of cellulose. In TEMPO-mediated oxidation, carboxylic and aldehyde groups are introduced into cellulose microfibrils. ${ }^{33}$ The modified cellulose surface is negatively charged which results in the repulsion of individual fibrils, thus reducing the energy demand. Similarly, Enzymatic treatment can largely reduce the energy consumption by cellulose surface degradation and is environmentally advantageous compared with chemical treatment.

The mechanical process usually starts with a diluted slurry of pretreated cellulose fibers, as the viscosity increases dramatically during the cyclic high pressure homogenization. ${ }^{34,35}$ With increasing degree of disintegration, the microfibrillated cellulose fibers achieve sufficient dispersion and convert to a viscous suspension. Finally, with a complete fibrillation, a gel consisting of strongly entangled MFC fibers is obtained.

\subsubsection{Structure of MFC}

Cellulose is a linear biopolymer composed of repeated $\beta$-D-glucose units (as shown in Figure 1.4). ${ }^{36}$ The degree of polymerization (DP) in raw material is reported to be over 10,000 ${ }^{29}$. During the growth of plant cell wall, bio-synthesized cellulose chains are assembled into the elementary cellulose microfibrils which have a diameter of 2-10nm and a length of tens of microns. ${ }^{27,37}$ Cellulose chains are parallel oriented and crystallized in the axis of the microfibril and randomly oriented around the crystal region. ${ }^{38}$ 
The isolated MFC fibers are often the aggregates of these microfibrils. The structure model of MFC cross-section is shown in Figure 1.5. The diameter of typical MFC fibers is in the range of 20 40nm. Its crystallinity can be higher than $70 \% .{ }^{39}$

\subsubsection{Modification of MFC}

The strong hydrophilic surface of MFC poses a barrier to realize its superior reinforcing ability in epoxy composites. In a non-polar polymer matrix like epoxy, the hydrophilic surface of MFC inhibits fiber dispersion causing a weak interface.

Several modifications were investigated to increase the reinforcing efficiency of cellulose fibers in non-polar matrices. Pasquini et $\mathrm{al}^{40}$ modified cellulose fibers with octadecanoyl and dodecanoyl chloride acids for LDPE composites. No significant change in mechanical properties was reported after modification, despite an improved compatibility. Lu et al. ${ }^{24}$ used 3aminopropyltriethoxysilane (APS) to functionalize MFC fibers and, obtained approximately a $25 \%$ increase in storage modulus for epoxy composites (as a comparison, 20\% increase was achieved with neat MFC) at a fiber content of $3.7 \mathrm{wt} . \%$. Similarly, Abdelmouleh et al. ${ }^{41}$ reinforced unsaturated polyester and epoxy with aminopropyltriethoxysilane (APS), hexadecytrimethoxysilane (HDS), methacrylopropyltrimethoxysilane (MPS), hexadecytrimethoxysilane, and mercaptopropyltrimethoxysilane (MRPS) treated cellulose fibers. At a fiber content of 40 vol. \%, epoxy composites achieved a storage modulus of $2.55 \mathrm{GPa}$ at $20{ }^{\circ} \mathrm{C}$ with the untreated cellulose fiber, $2.93 \mathrm{GPa}$ and 3.2 GPa with MRPS and APS treated 
cellulose fibers respectively. Anhydride and acetic acid etc. ${ }^{42}$ have also been used as modification reagents.

\subsection{Graphene oxide (GO)}

$\mathrm{GO}$ is a carbon atomic sheet comprised of sp2- and sp3- hybridized carbon atoms with carboxyl groups on its edge and hydroxyl groups, epoxide groups on its basal planes. Nonoxidized regions where carbon atoms preserved sp2- hybridization and conjugated structure of hexagonal graphic lattice are randomly distributed on the surface of GO. ${ }^{43}$ The structure model of GO is shown in Figure 1.6. GO sheet is nearly flat, despite some wrinkles caused by distorted configuration of hydroxyl groups attached to carbon atoms. Due to the existence of carboxylic group, the pristine GO dispersion is acidic.

The most widely used method for GO preparation was proposed by Hummers and Offeman in 1950s. ${ }^{44}$ Hummers' method is preferred due to its efficiency and safety. In hummers' method, the oxidation of graphite was accomplished in concentrated sulfuric acid solution with potassium hypermanganate $(\mathrm{KMnO} 4)$ and sodium nitrate (NaNO3). The oxidized graphite maintained the layered structure but each layer was heavily decorated with oxygen-containing functional groups, which expand the interlayer distance. As a result, GO, as monolayers of oxidized graphite, could be exfoliated in water under sonication.

Graphene-like sheets can be produced by the reduction of exfoliated GO. The reduction process is seen as the recovery of conjugated network of graphene. With the recovery of the 
conjugated structure, the reduced $\mathrm{GO}(\mathrm{rGO})$ regained partial electrical conductivity and mechanical property of pristine graphene. However, existing reduction methods are not able to reduce the graphene oxide completely. Residual functional groups remain on rGO and break the conjugated structure, which restrict rGO's properties.

Due to the presence of functional groups, GO can be easily dispersed in water or polar organic solvents, which facilitates its application as reinforcement in composites. 


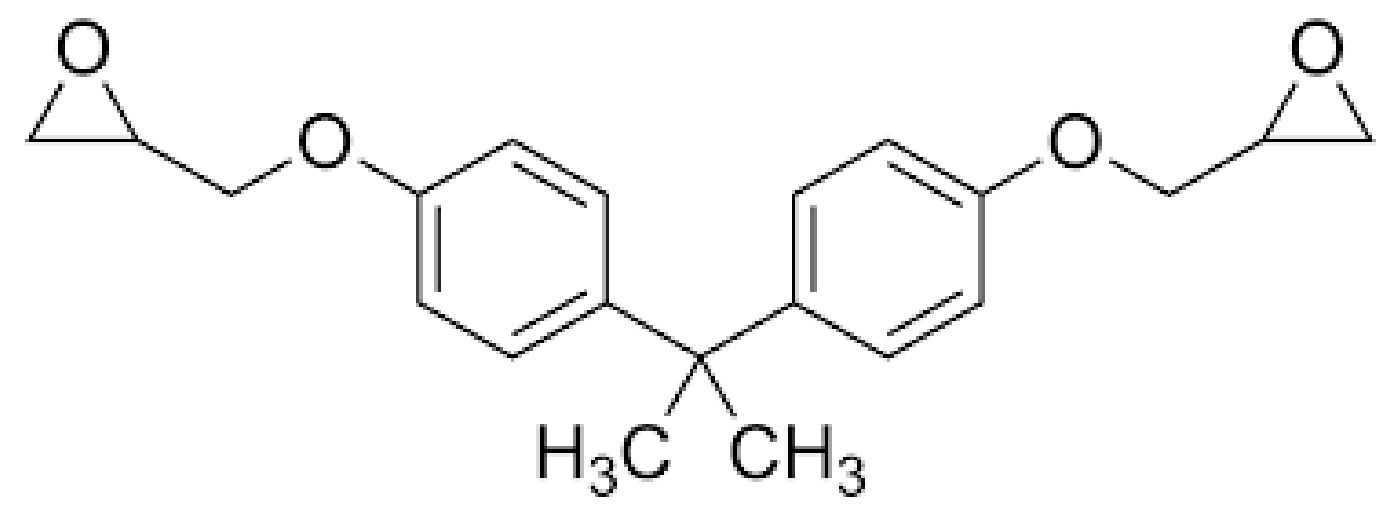

Fig 1.1 Chemical structure of DGEBA 


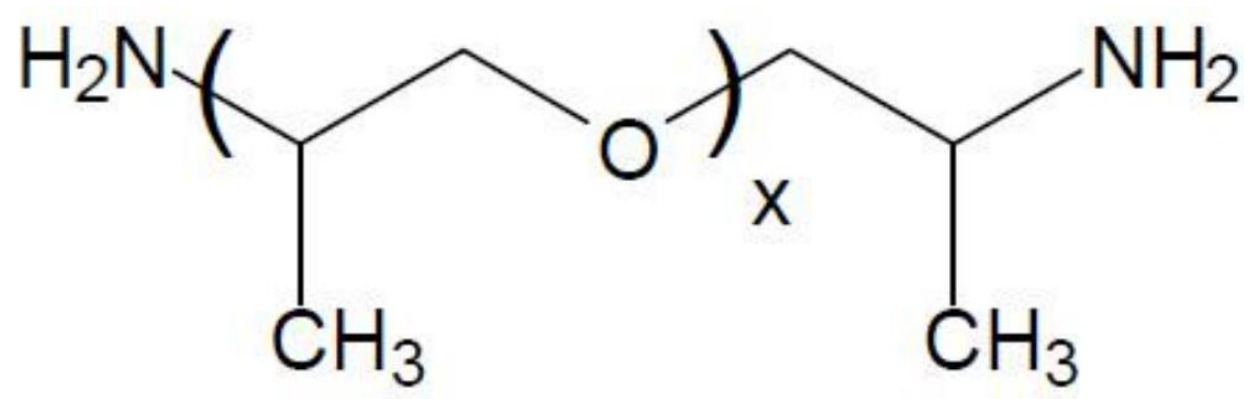

Figure1.2 Chemical structure of polyetheramines 

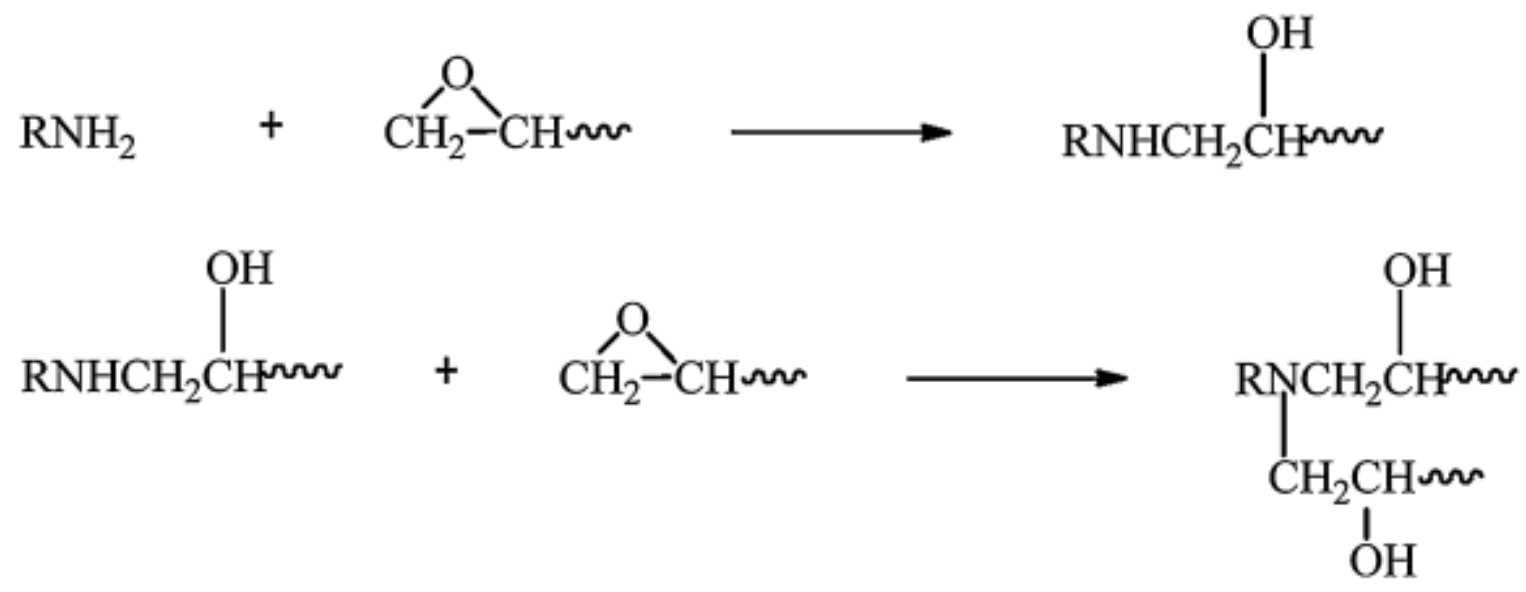

Figure 1.3 Curing mechanism of amine and epoxy ${ }^{1}$ 


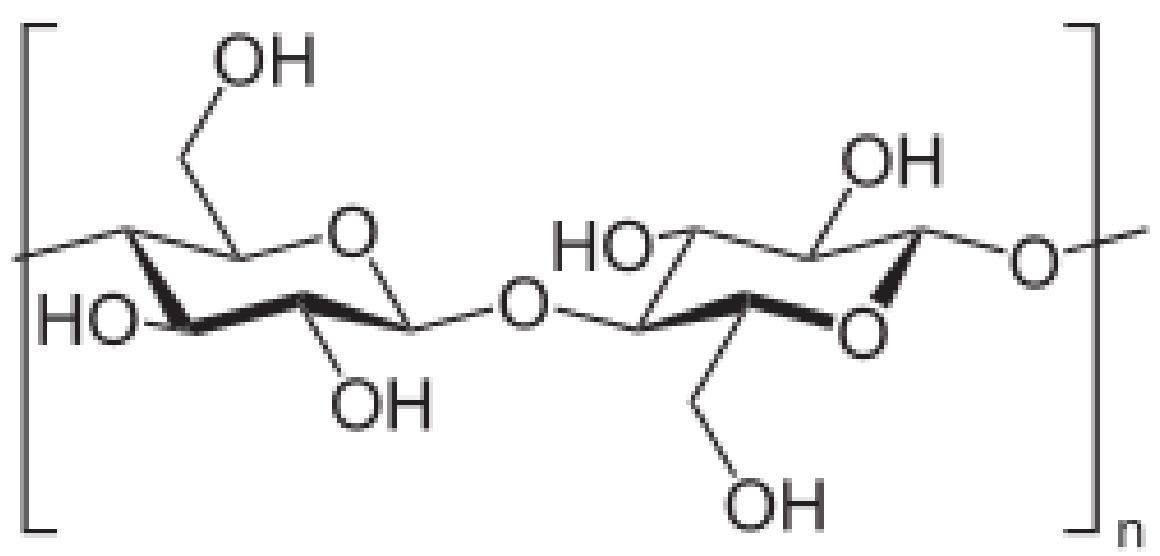

Figure 1.4 Chemical structure of cellulose 


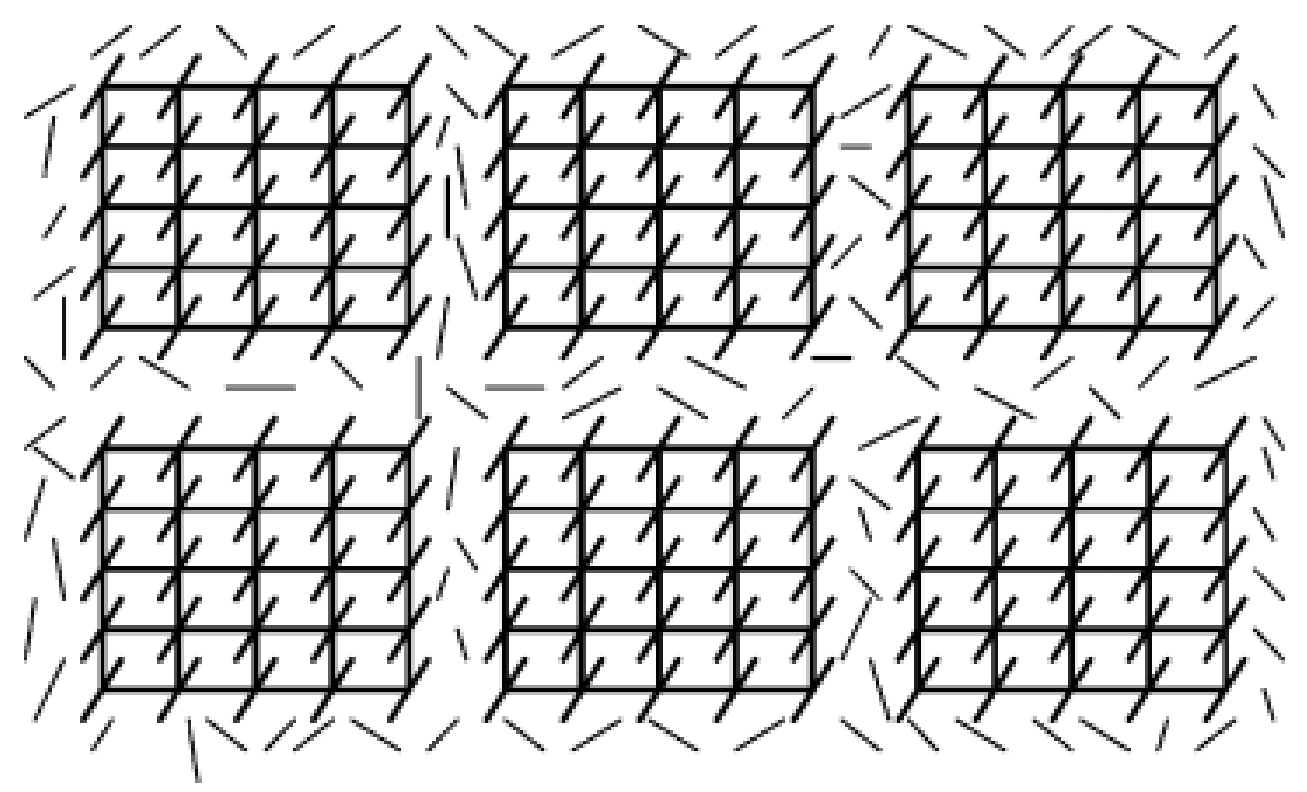

Figure 1.5 Cross-sectional structure model (Modified Frey-Wyssling model) of a cellulose nanofiber composed of six elementary fibrils, each small stick stands for a cellulose chain. ${ }^{45}$ 


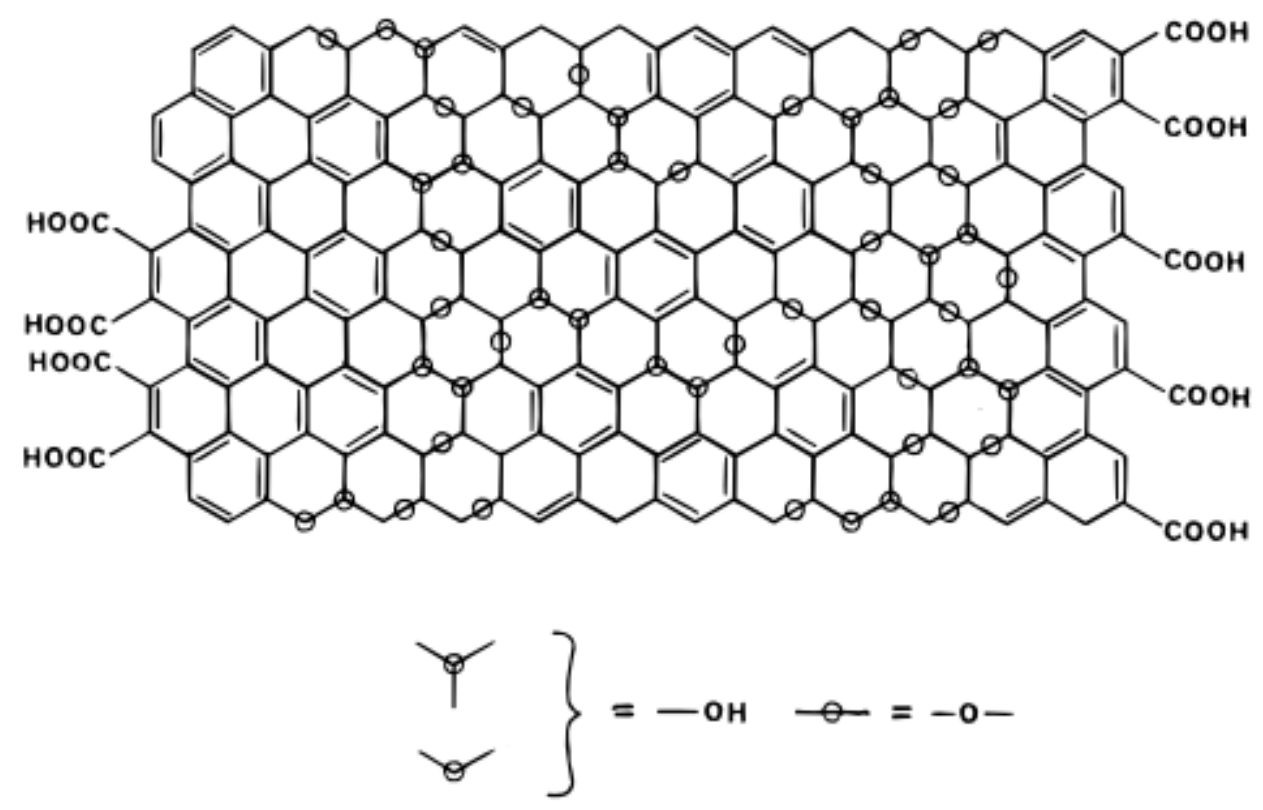

Figure 1.6 Structure model (Lerf-Klinowski model) of Graphene oxide. ${ }^{46}$ 


\section{Chapter 2}

\section{Experimental Section}

\subsection{Materials}

Epoxy resin DGEBA (Bisphenol A diglycidyl ether), sodium hydroxide( $\mathrm{NaOH})$, sodium nitrate $\left(\mathrm{NaNO}_{3}\right)$, hydrogen peroxide $\left(30 \% \mathrm{H}_{2} \mathrm{O}_{2}\right.$ solution) and concentrated sulfuric acid $\left(\mathrm{H}_{2} \mathrm{SO}_{4}\right)$ were purchased from Sigma-Aldrich. Epichlorohydrin $(\mathrm{ECH})$, potassium permanganate $\left(\mathrm{KMnO}_{4}\right)$ and hydrochloric acid ( $\mathrm{HCl}, 37 \%$ solution) were purchased from Fisher Scientific, Inc. Microfibrillated Cellulose (MFC) aqueous gel was provided by Weidmann Fiber Technology.

\subsection{Synthesis of Graphene Oxide}

Graphene oxide (GO) was synthesized from natural graphite powder (325mesh, from Alfa Aesar) using a modified Hummers' method. ${ }^{44}$ In brief, $3 \mathrm{~g}$ graphite and $1.5 \mathrm{~g}$ sodium nitrate were mixed together with $70 \mathrm{ml}$ concentrated sulfuric acid under stirring. 9 g $\mathrm{KMnO}_{4}$ was added gradually to solution in an ice-bath to prevent overheating. The mixture was stirred at $40{ }^{\circ} \mathrm{C}$ for 2 hours to ensure the completion of reaction. The mixture was diluted with $150 \mathrm{ml}$ DI water under vigorous stirring with an increase in temperature to $90{ }^{\circ} \mathrm{C}$ for 30 minutes and again diluted with $500 \mathrm{ml}$ of water. $15 \mathrm{ml} 30 \% \mathrm{H}_{2} \mathrm{O}_{2}$ solution was added to ensure the complete reaction with $\mathrm{KMnO}_{4}$. The resulting mixture was washed by $1: 10$ aqueous $\mathrm{HCl}$ solution and water respectively, then dialyzed in distilled water for a week. Graphene oxide aqueous dispersion was thus obtained. 


\subsection{Film/mat preparation}

\subsubsection{MFC film/mat preparation}

MFC gel was diluted from $3.48 \mathrm{wt} \%$ to $0.5 \mathrm{wt} \%$ suspension with distilled water and stirred for 1 hour to achieve good dispersion. Different amounts of diluted MFC suspension were filtrated with the same Buchner funnel to prepare wet cakes with different thicknesses. The obtained wet cakes were freeze-dried using a Scanvas Freeze-dryer at $-108{ }^{\circ} \mathrm{C}$ under high vacuum pumping to eliminate the water content and avoid shrinkage. Wet cakes were frozen with dry ice before transferring to freeze-dryer. Porous MFC mats with various thicknesses were thus obtained. Film samples were prepared by drying the wet cake in the air at room temperature for 3days.

\subsection{2 $\mathrm{MFC} / \mathrm{GO}$ Film/mat preparation}

MFC gel was diluted from 3.48 wt $\%$ to $0.5 \mathrm{wt} \%$ suspension with distilled water and stirred for 1 hour to achieve good dispersion. Then different weight ratios of graphene oxide ( 0 $\mathrm{wt} \%, 1 \mathrm{wt} \%, 2 \mathrm{wt} \%, 5 \mathrm{wt} \%, 10 \mathrm{wt} \%$ to MFC dry weight) were added to the diluted suspension of MFC under stirring.

Non-crosslinked samples: Diluted MFC aqueous suspension was filtered. The obtained wet cake was soaked in DI water to prevent water loss induced fiber aggregation.

Crosslinked samples: $9 \mathrm{ml}$ epichlorohydrin $(\mathrm{ECH})$ was added to the diluted suspension of MFC in DI water under continuous stirring. Then, the resulting mixture was put into an oven at 
$80{ }^{\circ} \mathrm{C}$ for $24 \mathrm{~h}$ after adding $0.5 \mathrm{~g} \mathrm{NaOH}$ to make the medium alkaline. The mechanism of crosslinking reaction between cellulose and GO with epichlorohydrin is shown in Figure 2.1. Epichlorohydrin can react with the hydroxyl group of MFC and GO in alkaline conditions to form the crosslinked MFC/GO product. The same reaction mechanism has been used in cellulose aerogel preparation and crosslinked chitosan beads preparation. ${ }^{47,48}$ Wet cakes obtained from the above suspension after vacuum filtration were washed with ethanol and distilled water. The wet cakes were then soaked in distilled water.

Finally, film samples were obtained by air-drying the wet cake at room temperature for 3days and porous mat samples were obtained via freeze-drying.

\subsection{Composites fabrication}

MFC/epoxy composites were prepared using an optimized impregnation method. To prepare the epoxy system, DGEBA and Jeffamine D230 which was chosen as the curing agent/hardener for this work were mixed in stoichiometric amounts. After elimination of air bubbles caused by mixing, the porous freeze-dried mats were placed on top of the epoxy/hardener mixture under vacuum. Impregnation of the monomeric mixture would cause the mat to sink thereby allowing further impregnation. The mat was left to infuse with epoxy overnight. The weight ratio of fiber reinforcement material was controlled by compression molding. Curing of the composites was done at $80{ }^{\circ} \mathrm{C}$ for $4 \mathrm{~h}$ and $120{ }^{\circ} \mathrm{C}$ for another $4 \mathrm{~h}$. 
Glass fiber/epoxy composites and crosslinked MFC/GO epoxy composites sample were prepared with the same optimized impregnation method used in MFC/epoxy composites fabrication. All composites were prepared with a fiber content of 15 vol. \%.

GO/epoxy composites samples were prepared using a solvent exchange method to get uniform dispersion. The aqueous GO suspension was solvent exchanged with DMF and then mixed with DGEBA and Jeffamine D230. The resultant mixture was cured in a vacuum oven for $24 \mathrm{~h}$ at $80{ }^{\circ} \mathrm{C}$ and $12 \mathrm{~h}$ at $120{ }^{\circ} \mathrm{C}$ for complete removal of DMF. Epoxy composites with 0.4 wt $\%, 1 \mathrm{wt} \%, 2 \mathrm{wt} \% \mathrm{GO}$ were prepared.

\subsection{Characterization}

Fourier transform infrared (FTIR) spectroscopy

IR spectra of the crosslinked and non-crosslinked samples were obtained using a Nicolet iS50R FTIR Spectrometer. Samples for FTIR were prepared by solution casting on PTFE paper and dried in the vacuum oven at $60{ }^{\circ} \mathrm{C}$ for 24 hours. ATR-FTIR spectra of graphene oxide, ECH treated graphene oxide and sodium hydroxide treated graphene oxide were obtained using the same instrument. All IR spectra are presented with baseline correction

Tensile testing

Tensile testing was done using an MTS instrument (model 2525-806, MTS System Corporation, MN, US) at room temperature with a loading speed of $0.3 \mathrm{~mm} / \mathrm{min}$. The samples for tensile testing were rectangle shaped with a thickness around $0.3 \mathrm{~mm}$. The data was averaged over 3-4 specimens. 
Specific surface area and pore size distribution

The Brunauer-Emmett-Teller (BET) surface area was measured by N2 physisorption using Tristar II 3020 surface area analyzer. 100 -150 mg of porous mat sample was first degassed at $150{ }^{\circ} \mathrm{C}$ for $4 \mathrm{~h}$ prior to the analysis. BET analysis was carried out at $77 \mathrm{k}$ to determine the specific surface area and the Barrett-Joyner-Halenda (BJH) pore size distribution.

Water contact angle

The contact angle of water on the crosslinked GO/MFC and non-crosslinked GO/MFC films was measured using FDS Dataphysics Contact Analyzer at room temperature in air. The water contact angle was averaged over three measurements.

Scanning electron microscopy (SEM)

The morphology of crosslinked MFC/GO mat was analyzed using a FEI Nova Nanolab 200 instrument at accelerating voltage of $3 \mathrm{kv}$. Samples were sputtered coated with Palladium prior to imaging.

XRD

XRD was conducted using the Bruker Discover D8 X-ray diffractometer with Co $\mathrm{K} \alpha$ radiation in the range of $5-40^{\circ}$ at room temperature.

Dynamic mechanical analysis (DMA)

Storage modulus and glass transition temperature $(\mathrm{Tg})$ were determined with Q800 from TA instruments in single/dual cantilever mode with a constant frequency of $1 \mathrm{~Hz}$, strain amplitude 
of $0.5 \%$ and a temperature range of $40-200{ }^{\circ} \mathrm{C}$ at a rate of $4{ }^{\circ} \mathrm{C} / \mathrm{min}$. Three specimens were tested for each sample to ensure reproducibility.

Thermal gravimetric analysis (TGA)

The thermal stability of epoxy composites was investigated using a TA instruments Q500 with a platinum pan heated from room temperature to $600{ }^{\circ} \mathrm{C}$ with a heating rate of $10{ }^{\circ} \mathrm{C} / \mathrm{min}$ in a nitrogen environment. The sample weight ranged from 8 to $10 \mathrm{mg}$. 


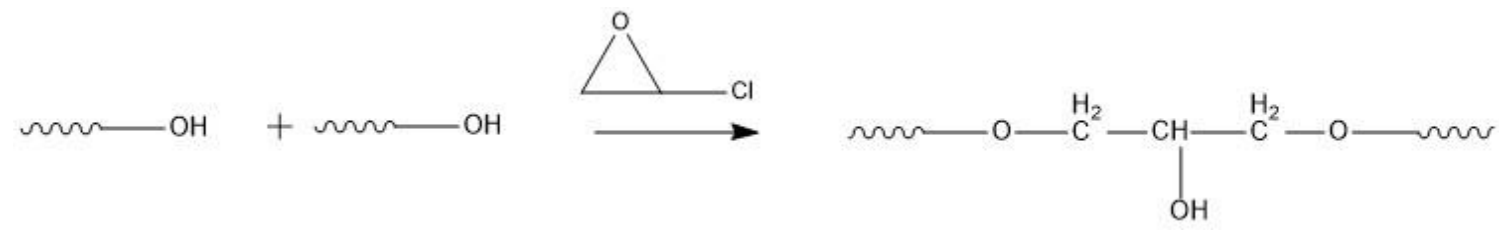

Figure 2.1 Crosslinking reaction between hydroxyl groups and epichlorohydrin 


\section{Chapter 3}

\section{Results and discussion}

\subsection{Optimization of the composites fabrication process}

The aggregation of MFC fibers is inevitable and irreversible during the drying process. Strong fiber aggregation leads to shrinkage and low porosity of MFC samples, which may prevent the infusion of epoxy. The drying methods highly influence aggregation of MFC fibers. The porosity of freeze-dried and air-dried MFC samples were calculated form equation (1) where

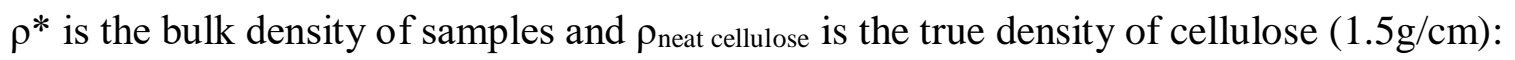

$$
\text { porosity }=1-\frac{\rho_{*}}{\rho_{\text {neat cellulose }}}
$$

The calculated porosities of dried MFC samples are shown in Table 3.1. The freeze-drying method inhibited the fiber aggregation and resulted in a much higher porosity as compared with air-dried sample. The porosity of freeze-dried MFC mats remain the same with a varied thickness. As shown in Figure 3.1, the freeze-dried sample has an open pore network, which allows the infusion of epoxy, while the air-dried sample suffered a significant shrinkage and showed a closed surface. Therefore, freeze-dried mats were used in composites fabrication.

In addition, to check the influence of mat thickness, MFC/epoxy composites were prepared using MFC mats with different thicknesses at a constant pressure in compression molding. The volume ratio $(\Phi)$ of each component of the composite was calculated from the equations listed below: 


$$
\begin{gathered}
\Phi_{M F C}=\frac{W_{M F C}}{\rho_{M F C} \times V_{c}} \times 100 \% \\
\Phi_{\text {epoxy }}=\frac{W_{c}-W_{M F C}}{\rho_{\text {epoxy }} \times V_{c}} \times 100 \% \\
\Phi_{\text {air }}=\left(1-\Phi_{M F C}-\Phi_{\text {epoxy }}\right) \times 100 \%
\end{gathered}
$$

Where $\mathrm{W}_{\mathrm{MFC}}$ is the weight of MFC mat, $\mathrm{W}_{\mathrm{c}}$ is the weight of total composite, $\mathrm{V}_{\mathrm{c}}$ is the total volume of composite, $\rho_{\text {MFC }}$ is the true density of MFC and $\rho_{\text {epoxy }}$ is the density of neat epoxy.

Results are shown in Table 3.2. With increasing in mat thickness, the air content in composites increases dramatically. Infusion process takes more time for a thick mat as epoxy is infused in the thickness direction. The viscosity of epoxy/hardener mixture gradually increases during the infusion process since the curing of epoxy/Jeffamine D230 can occur at room temperature, which may result in an incomplete epoxy infusion. The air voids can largely decrease the properties of MFC/epoxy composites. With a slightly higher volume ratio of MFC, the storage modulus of the composite containing 25.8 vol. $\%$ air at $40^{\circ} \mathrm{C}$ is only half of that of the composite with 1.3 vol. \% air (see Figure 3.2). So, when preparing crosslinked MFC/GO epoxy composites, each mat was prepared with less than $50 \mathrm{ml} 0.5 \mathrm{wt} . \%$ MFC suspension to control the mat thickness to avoid excessive air content.

\subsection{Characterization of film/mat}

\subsubsection{FTIR}


To study the reaction between MFC, GO with ECH, the chemical structure of GO, $\mathrm{NaOH}$ treated GO, ECH modified GO, crosslinked MFC/GO and non-crosslinked MFC/GO were investigated by FTIR and shown in Figure 3.2.1 (a) and (b). Graphene Oxide (GO) has a hydrophilic surface with oxygen-rich functional groups. The ATR-FTIR spectra of GO samples show characteristic peaks for hydroxyl group (-OH stretching $\left.3400 \mathrm{~cm}^{-1}\right)$, epoxide group (C-O stretching $\left.1260 \mathrm{~cm}^{-1}\right)$, carboxyl group $\left(\mathrm{C}=\mathrm{O}\right.$ stretching $\left.1650 \mathrm{~cm}^{-1}\right)$ and carbonyl group $(\mathrm{C}=\mathrm{O}$ stretching $\left.1750 \mathrm{~cm}^{-1}\right)$. The drop in the intensity of these peaks for $\mathrm{NaOH}$ treated $\mathrm{GO}$ compared to pristine GO is due to the reduction of GO with sodium hydroxide at elevated temperature. ${ }^{49}$ After reacting with $\mathrm{ECH}$, the increasing intensities of peaks at $3400 \mathrm{~cm}-1$ were induced by the formation of ether groups on GO surface and hydrolysis of grafted ECH.

The FTIR spectra of Crosslinked and Non-crosslinked MFC/GO film (Figure 3.3 (b)) show characteristic peaks for $-\mathrm{OH}$ stretching $\left(3400 \mathrm{~cm}^{-1}\right), \mathrm{C}-\mathrm{H}$ stretching $\left(2900 \mathrm{~cm}^{-1}\right)$, O-H bending $\left(1375 \mathrm{~cm}^{-1}\right)$ and C-O-C asymmetric stretching $\left(1060 \mathrm{~cm}^{-1}\right)$. The FTIR was normalized with the peak at $897 \mathrm{~cm}-1$ as it is the peak for $\mathrm{C} 1-\mathrm{H}$ deformation of glucose rings. ${ }^{50}$ The decreased intensity of $-\mathrm{OH}\left(3400 \mathrm{~cm}^{-1}\right)$ peak for crosslinked MFC/GO is believed to be caused by the crosslinking reaction between hydroxyl groups of MFC or GO with ECH. During the reaction, ECH consumed two hydroxyl groups and generated a new hydroxyl group which results in the decrease in the amount of hydroxyl groups.

\subsubsection{BET surface area analysis}

In order to study the effect of graphene oxide and its crosslinking on aggregation of MFC nanofibers, the specific surface area of crosslinked and non-crosslinked MFC/GO mat were 
measured (Figure 3.4 (a)). Surface area of the non-crosslinked sample ranges from 10 to $23 \mathrm{~m}^{2} / \mathrm{g}$. By comparison, the surface area of crosslinked mats is much larger (range from 32 to over 45 $\mathrm{m}^{2} / \mathrm{g}$ ). We believe that crosslinking between graphene and the MFC fiber immobilized the network preventing fiber aggregation during vacuum pumping or freeze-drying processes. Moreover, MFC is known to act as a nano-spacer and effectively prevent the aggregation of GO sheets. ${ }^{51,52}$ The large specific surface area of GO contributed to the increases in surface area of the crosslinked GO/MFC mat. ${ }^{53}$ The surface area reached the highest with $2 \mathrm{wt} \% \mathrm{GO}$ and slightly decreased at higher GO loading. The decrease can be attributed to agglomeration and overlap of GO sheets at higher GO concentrations.

Microfibrillated cellulose is an excellent mesopore maker with a diameter between 2 and $50 \mathrm{~nm} .{ }^{52}$ The BJH method has been used to estimate the pore size distribution for crosslinked and non-crosslinked MFC/GO mats. The curve of pore size distribution shows the pore diameter in the range of 2-100 $\mathrm{nm}$. Surface area of non-crosslinked mats decreased dramatically with the loading of graphene oxide. The mesoporosity of non-crosslinked MFC/GO mats decreased with an increasing amount of GO, indicating the blocking of mesopores by GO. The mesoporosity of crosslinked MFC/GO showed no difference to crosslinked MFC mat since chemical crosslinking has stabilized the MFC fiber network.

\subsubsection{MFC/GO morphology}

Figure 3.5 (a) shows the morphology of crosslinked $2 \mathrm{wt} \%$-GO/MFC porous mat prepared by freeze-drying. An entangled porous network is clearly seen in the picture. GO sheets were 
found attached or embedded on the MFC fibers. While crosslinking prevented the aggregation of MFC to some extent, SEM image shows that aggregation of MFC fibers still exist. In the case of non-crosslinked mat sample, GO sheets formed large area of aggregates on MFC fibers and blocked the mesopores resulting in a smooth surface area (see Figure 3.5(b)).

\subsubsection{Water Contact Angle}

Water contact angle was measured to study the hydrophobicity change after crosslinking. The water contact angles of all film samples increased after reacting with ECH. The water contact angle of GO could not be measured since water completely wet the extremely hydrophilic GO film surface. The neat MFC film gave a water contact angle of $40^{\circ}$. Crosslinked films showed an increased water contact angle around $90-100^{\circ}$ (Figure 3.6), which is close to the result achieved from ECH crosslinked regenerated cellulose film ${ }^{54}$. The mass fraction changes of GO in air-dried film did not have any discernible influences on contact angle of both crosslinked and non-crosslinked film samples. The increased water contact angle is believed to be caused by ECH grafting. The hydrophobicity change was expected to improve the interfacial adhesion between MFC and epoxy matrix.

\subsubsection{XRD}

The influence of crosslinking reaction on MFC crystal structure was analyzed by X-ray diffraction. The XRD patterns for crosslinked and non-crosslinked cellulose mat (Figure 3.7) are similar. The two broad peaks exhibited at $19^{\circ}$ and $26.1^{\circ}$ are the characteristic peaks of

Cellulose I crystal structure ${ }^{55,56}$. Though the XRD pattern of crosslinked MFC mat showed a 
decrease and broadening peak at $26.1^{\circ}$, the Cellulose I crystal structure of MFC was preserved during crosslinking reaction. Segal equation ${ }^{57}$ was applied to calculate the degree of crystallinity.

$$
I c=\frac{\text { I002-Iamorphous }}{I 002} \times 100 \%
$$

Where $\mathrm{I}_{002}$ is the maximum intensity of the (002) lattice diffraction; and I amorphous is the intensity diffraction of the amorphous band.

The crystallinity index slightly decreased from $73.4 \%$ for the non-crosslinked mat to $66.2 \%$ for the crosslinked mat. The drop in crystallinity is expected due to restricted chain movement induced by crosslinking. Other works have also reported a drop in crystallinity with modification of nanocellulose. ${ }^{58-60}$ The decrease in crystallinity is not the only factor determining the composites as reported by Abraham et al. ${ }^{61}$ While the crystallinity of CNC decreased from $78.9 \%$ to $42.1 \%$ after acetylation, the modified CNC still showed an outstanding reinforcing capability in epoxy matrix with an increase in modulus of $98 \%$ with only $0.5 \mathrm{wt} \%$ of acetylated $\mathrm{CNC}^{61}$

The crosslinking reaction between MFC and GO was confirmed by FTIR and SEM. An increase in specific surface area was found. MFC preserved most of the crystalline structure and slightly decreased its crystallinity after the reaction. It was also found that GO could largely increase the tensile modulus and strength of MFC films (Figure 3.8).

\subsection{Characterization of Composites}




\subsubsection{Dynamic mechanical analysis}

The thermomechanical properties of composites were investigated with DMA. Figure 3.9 shows the storage modulus of neat epoxy, and MFC/epoxy composites. Storage modulus gradually increased with the increasing volume ratio of MFC. At $40{ }^{\circ} \mathrm{C}$ the 18 vol $\% \mathrm{MFC} / \mathrm{epoxy}$ composites showed a storage modulus of $5.8 \mathrm{GPa}$, which is about 3 times higher than the neat epoxy (2.0 GPa).

In the rubbery stage, where the matrix contribution is not significant, the MFC reinforcing effect was more clearly observed. The storage modulus of MFC composites at $150{ }^{\circ} \mathrm{C}$ increased about 450 times with 18 vol \% MFC compared to the neat epoxy (2.06 GPa and $0.007 \mathrm{GPa}$ respectively). This is already higher than the reinforcement conveyed by conventional glass fibers at $150{ }^{\circ} \mathrm{C}(1.5 \mathrm{GPa})$ at a similar fiber volume content. However, in most structural applications, epoxy composites are typically used below their glass transition temperature making the mechanical properties in the glassy state desirable. The glass fiber reinforcement below Tg is higher than that observed for the MFC at similar volume ratios. If MFC can truly be a glass fiber replacement, the glassy state mechanical properties of the composite need to be increased.

Storage modulus of crosslinked MFC/epoxy composites and crosslinked MFC/GO composites is shown in Figure 3.10 (a ). Storage modulus of crosslinked MFC epoxy composites increased slightly compared to that of non-crosslinked MFC/epoxy composites. Crosslinked 2 wt \% GO-MFC/epoxy composites achieved the highest storage modulus in rubbery state (2.6 $\mathrm{GPa}$ at $\left.150{ }^{\circ} \mathrm{C}\right)$, followed by $10 \mathrm{wt} \% \mathrm{GO}\left(2.4 \mathrm{GPa}\right.$ at $\left.150^{\circ} \mathrm{C}\right)$ and $5 \mathrm{wt} \% \mathrm{GO}\left(2.2 \mathrm{GPa}\right.$ at $\left.150^{\circ} \mathrm{C}\right)$. 
Storage modulus of GO/MFC epoxy composites in glassy state increases with GO loading up to $2 \mathrm{wt} \%(0.4 \mathrm{wt} \%$ to the composites) and then decreases at higher GO loadings. Epoxy composite with 15 vol\% MFC/GO-2 wt \% exhibit a storage modulus of $6.5 \mathrm{GPa}$ at $40{ }^{\circ} \mathrm{C}, 2.6 \mathrm{GPa}$ at $150{ }^{\circ} \mathrm{C}$, which is higher than that of 15 vol \% glass fiber/epoxy composites both in glassy and rubbery state. After normalizing the storage modulus with the relative density, the superiority of crosslinked MFC/GO epoxy composites becomes more obvious (as shown in Table 3.3). Reinforcing efficiency of MFC was improved via GO crosslinking. A comparison between glass fiber/epoxy composites, crosslinked MFC/GO-2 wt \% epoxy composites is shown in Figure 3.10 (b).

GO possesses an extremely high elastic modulus up to $0.25 \mathrm{TPa}^{53,62}$. Though GO alone can reinforce the epoxy composites, however it is not as efficient as in the crosslinked GO/MFC epoxy composites. The thermomechanical property of GO/epoxy composites was studied (Figure 3.11). The storage modulus of GO/epoxy composites increases with the GO loading. However, due to the inevitable agglomeration of GO in epoxy composites, the reinforcement was limited at high GO concentration. ${ }^{63}$ With $0.4 \mathrm{wt} \%, 1 \mathrm{wt} \%$ and $2 \mathrm{wt} \% \mathrm{GO}$, the storage modulus of epoxy composites at $40{ }^{\circ} \mathrm{C}$ increased to $0.8 \mathrm{GPa}, 1.1 \mathrm{GPa}$ and $1.1 \mathrm{GPa}$ respectively. With the same GO loading of 0.4 wt. \%, the storage modulus of crosslinked 2 wt $\%$ GOMFC/epoxy composite increased to $6.5 \mathrm{GPa}$ at $40{ }^{\circ} \mathrm{C}$ and $2.56 \mathrm{GPa}$ at $150{ }^{\circ} \mathrm{C}$. The explanation could be that agglomeration of GO was restrained by crosslinking with MFC and with a fiber built network, GO achieved homogeneous dispersion in the epoxy composites. With a fiber network template, the distribution of GO sheet was constrained, resulting in more efficient reinforcing for crosslinked $\mathrm{MFC} / \mathrm{GO}$ at high temperature. 
The curves of $\tan \delta$ versus temperature for MFC/epoxy composites and neat epoxy are plotted in Figure 3.10 (c). Glass transition temperature ( $\mathrm{Tg}$ ) of MFC/epoxy composites obtained from the peak position of $\tan \delta$ is close to the neat epoxy.

\subsubsection{Tensile properties}

The mechanical properties of MFC/epoxy, crosslinked GO-MFC/epoxy were analyzed using tensile testing. The tensile modulus, tensile strength and strain at break of MFC/epoxy composites and crosslinked MFC-GO/epoxy composites with same amount of MFC content are shown in Figure 3.12. All crosslinked MFC-GO/epoxy composites show higher tensile modulus and tensile strength compared with MFC/epoxy composites with similar strain at break values. The 2 wt \% GO/MFC epoxy composite achieved the best performance among all the samples. The tensile modulus of MFC/epoxy composites increased by $40 \%$ with 2 wt $\%(0.4$ wt $\%$ to the total weight of composites) GO loading. The result shows the similar trend with DMA testing.

\subsubsection{Thermal stability}

Thermal gravimetric analysis (TGA) was used to study the thermal stability of MFC/epoxy and MFC/GO-epoxy composites with 15 vol \% fiber content. The results are shown in Figure 3.13. The thermal stability of composites is almost the same compared to the neat epoxy. The maximum weight loss of all the composites occurred in the temperature range of $389-398{ }^{\circ} \mathrm{C}$. 
Table 3.1 Porosity of MFC samples prepared with different drying methods

\begin{tabular}{|c|c|c|c|c|}
\hline $\begin{array}{l}\text { Suspension } \\
\text { Volume }\end{array}$ & $\begin{array}{l}\text { Thickness } \\
\text { (mm) }\end{array}$ & Weight (mg) & Porosity (\%) & Drying method \\
\hline $25 \mathrm{ml}$ & $0.18-0.19$ & $133-146$ & $87.5-88.0$ & Freeze-dry \\
\hline $50 \mathrm{ml}$ & $0.36-0.39$ & $273-274$ & $87.0-88.3$ & Freeze-dry \\
\hline $75 \mathrm{ml}$ & $0.54-0.56$ & 388-395 & $87.7-88.1$ & Freeze-dry \\
\hline $125 \mathrm{ml}$ & $0.67-0.74$ & $678-680$ & $82.6-83.7$ & Freeze-dry \\
\hline $125 \mathrm{ml}$ & $0.36-41$ & $727-940$ & $33.9-41.2$ & Air-dry \\
\hline
\end{tabular}


Table 3.2 Weight ratio and volume ratio of each components in MFC/epoxy composites

\begin{tabular}{|c|c|c|c|c|}
\hline $\begin{array}{l}\text { Mat thickness } \\
(\mathrm{mm})\end{array}$ & $\begin{array}{l}\text { Weight ratio of } \\
\operatorname{MFC}(\%)\end{array}$ & $\begin{array}{l}\text { Weight ratio of } \\
\text { epoxy }(\%)\end{array}$ & $\begin{array}{l}\text { Volume ratio of } \\
\operatorname{MFC}(\%)\end{array}$ & $\begin{array}{l}\text { Volume ratio of } \\
\text { air }(\%)\end{array}$ \\
\hline $0.18-0.19$ & 27.7 & 77.0 & 21.7 & 1.3 \\
\hline $0.36-0.39$ & 27.1 & 71.3 & 19.4 & 9.2 \\
\hline $0.54-0.56$ & 34.7 & 57.8 & 22.5 & 19.5 \\
\hline $0.67-0.74$ & 39.5 & 50.0 & 24.0 & 25.8 \\
\hline
\end{tabular}


Table 3.3 Storage Modulus normalized by relative density

\begin{tabular}{|c|c|c|c|c|}
\hline $\begin{array}{l}\text { Epoxy composites } \\
\text { Samples }\end{array}$ & $\begin{array}{l}\mathrm{E}^{6} 40^{\circ} \mathrm{C} \\
(\mathbf{G P a})\end{array}$ & $\operatorname{Density}\left(\mathrm{g} / \mathrm{cm}^{3}\right.$ & $\begin{array}{l}\text { Relative } \\
\text { density }\end{array}$ & $\begin{array}{l}\mathrm{E}^{{ }^{6}}{ }_{40^{\circ} \mathrm{C}} \\
\text { normalized(GPa) }\end{array}$ \\
\hline Neat epoxy & 2.06 & 1.10 & 1.00 & 2.06 \\
\hline 15 vol\% MFC & 4.89 & 1.14 & 1.03 & 4.72 \\
\hline 15 vol $\% \mathrm{MFC}+1 \mathrm{wt} \% \mathrm{GO}$ & 5.50 & 1.13 & 1.03 & 5.35 \\
\hline 15 vol $\% \mathrm{MFC}+2 \mathrm{wt} \% \mathrm{GO}$ & 6.54 & 1.09 & 0.99 & 6.60 \\
\hline 15 vol $\% \mathrm{MFC}+5 \mathrm{wt} \% \mathrm{GO}$ & 5.50 & 0.98 & 0.89 & 6.17 \\
\hline 15 vol\% MFC+10wt $\% \mathrm{GO}$ & 4.87 & 0.94 & 0.85 & 5.70 \\
\hline 15 vol\% Glass fiber & 6.00 & 1.31 & 1.19 & 5.00 \\
\hline
\end{tabular}




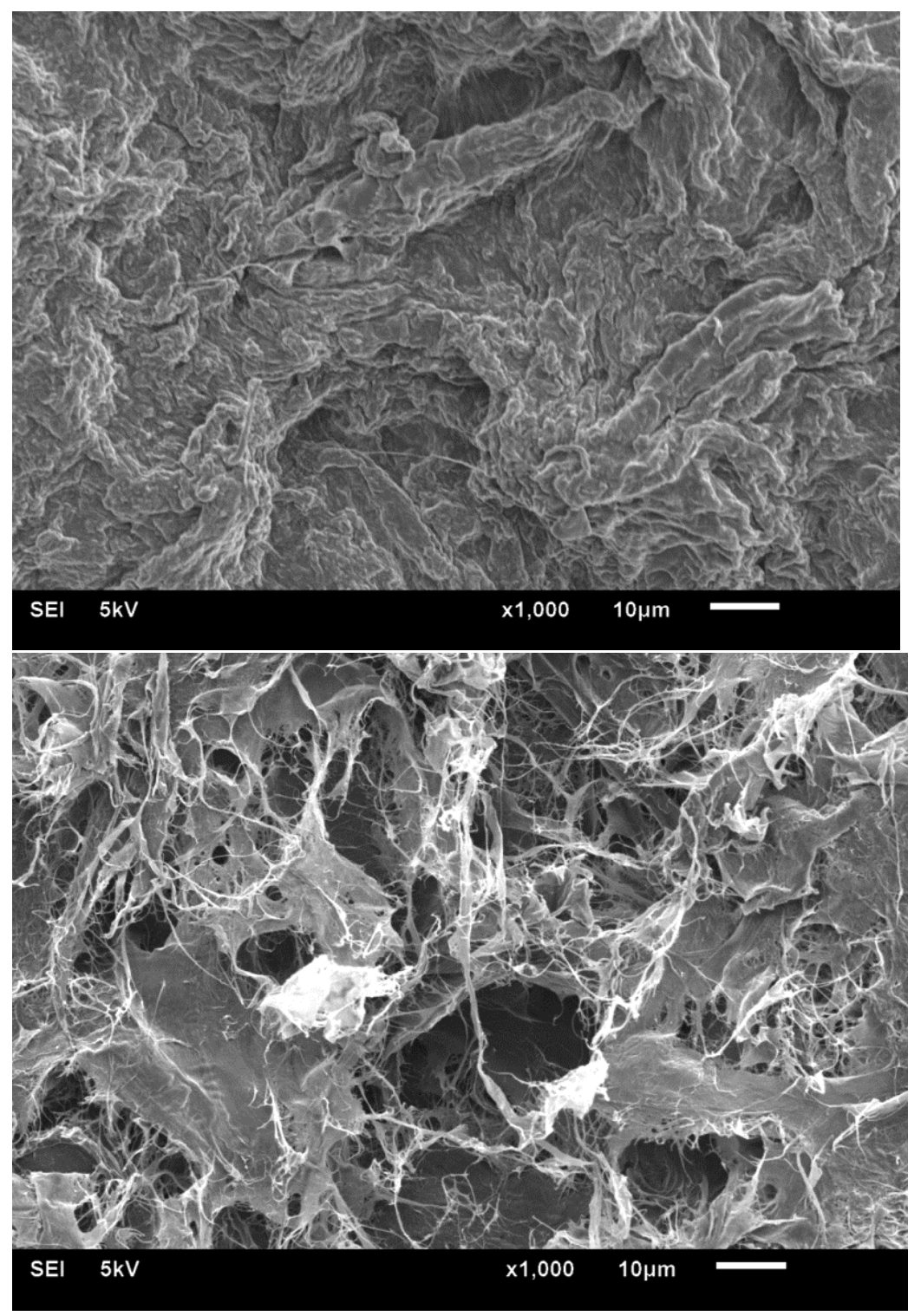

Figure 3.1 SEM images of air-dried MFC samples (up) and freeze-dried MFC samples (bottom) 


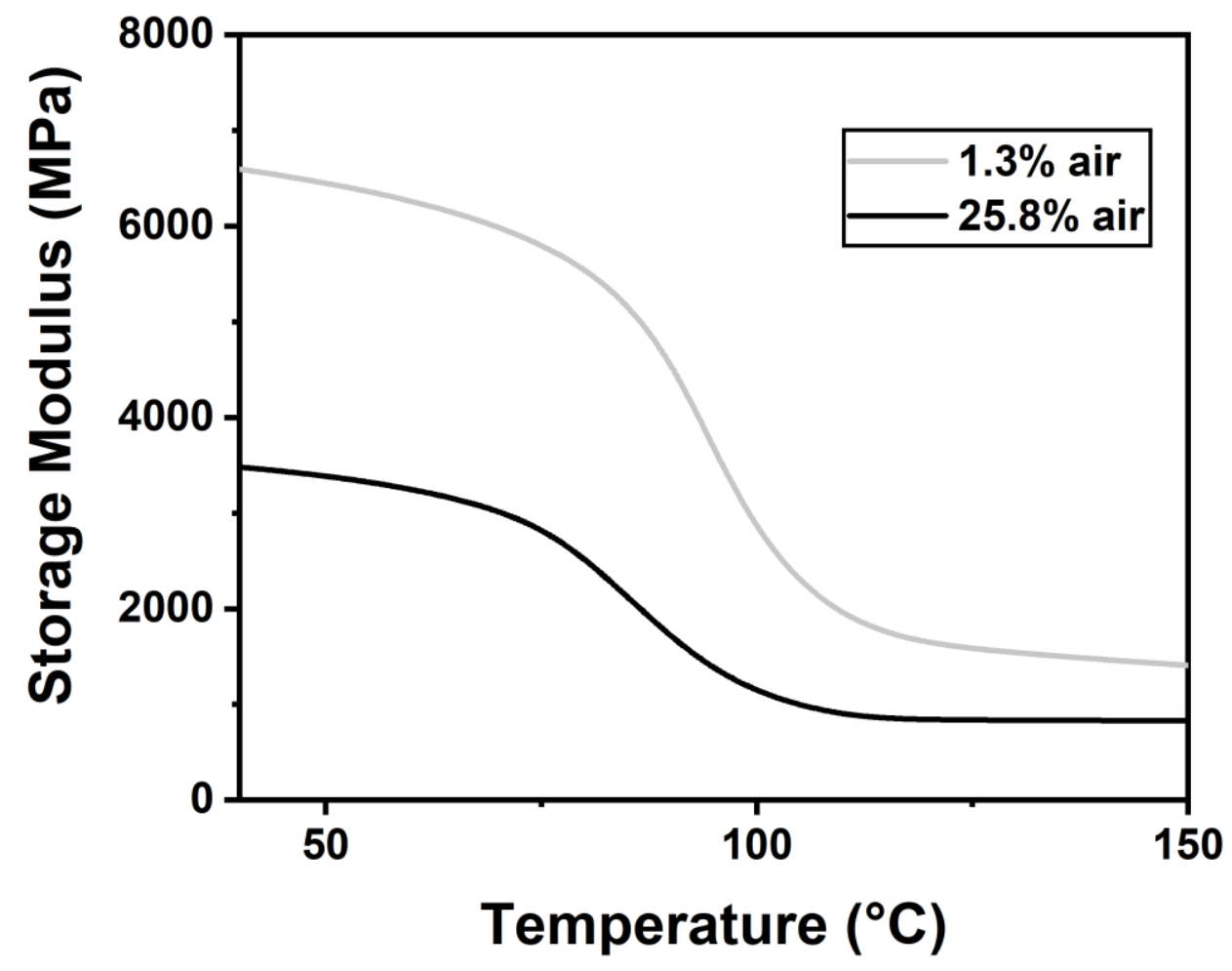

Figure 3.2 Storage modulus of MFC/epoxy composites with different volume ratio of air content 

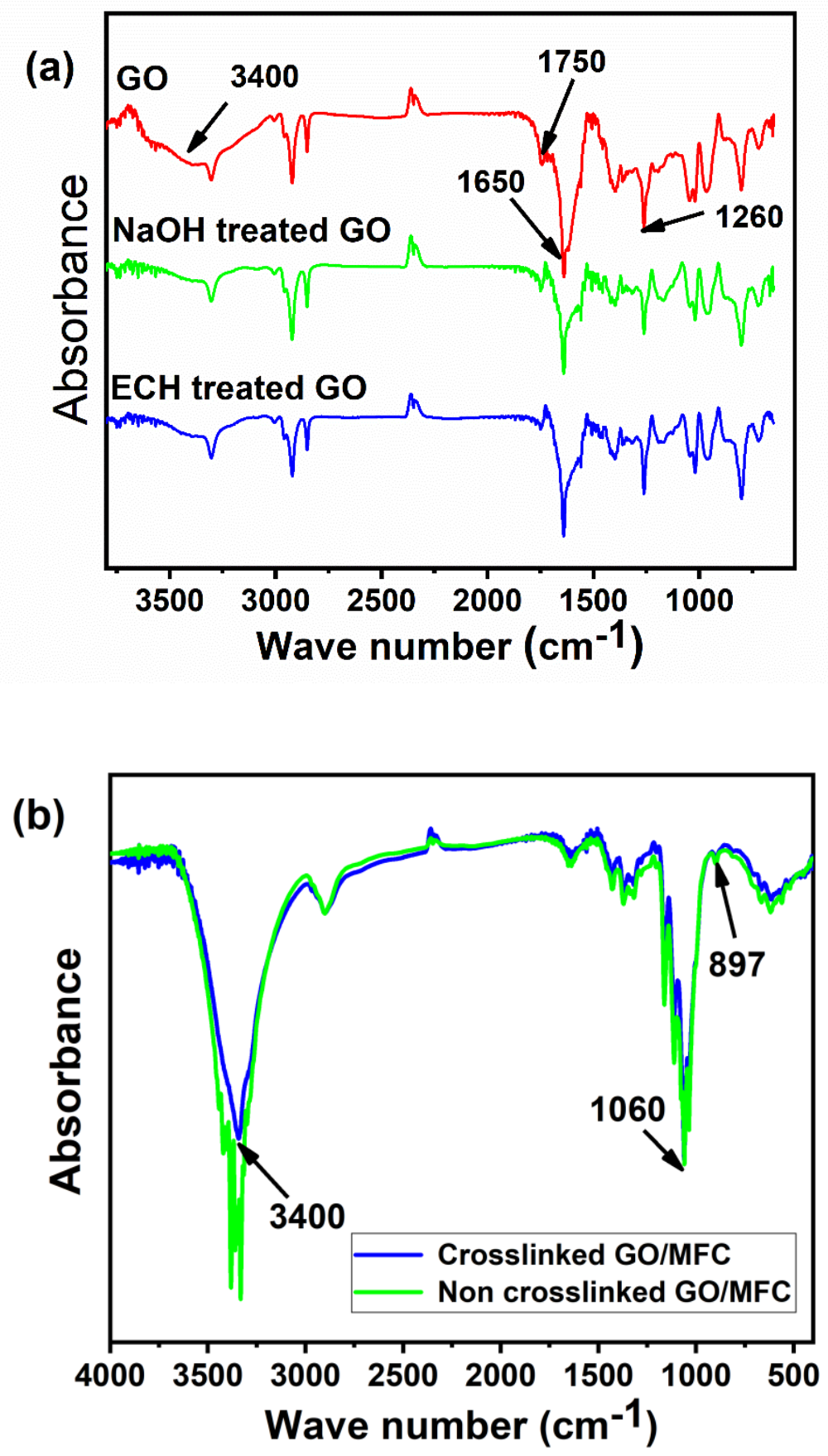

Figure 3.3 (a) ATR-FTIR of GO, $\mathrm{NaOH}$ treated $\mathrm{GO}$ and ECH modified GO; (b) FTIR of Crosslinked GO/MFC film and Non-crosslinked GO/MFC film 
(a)

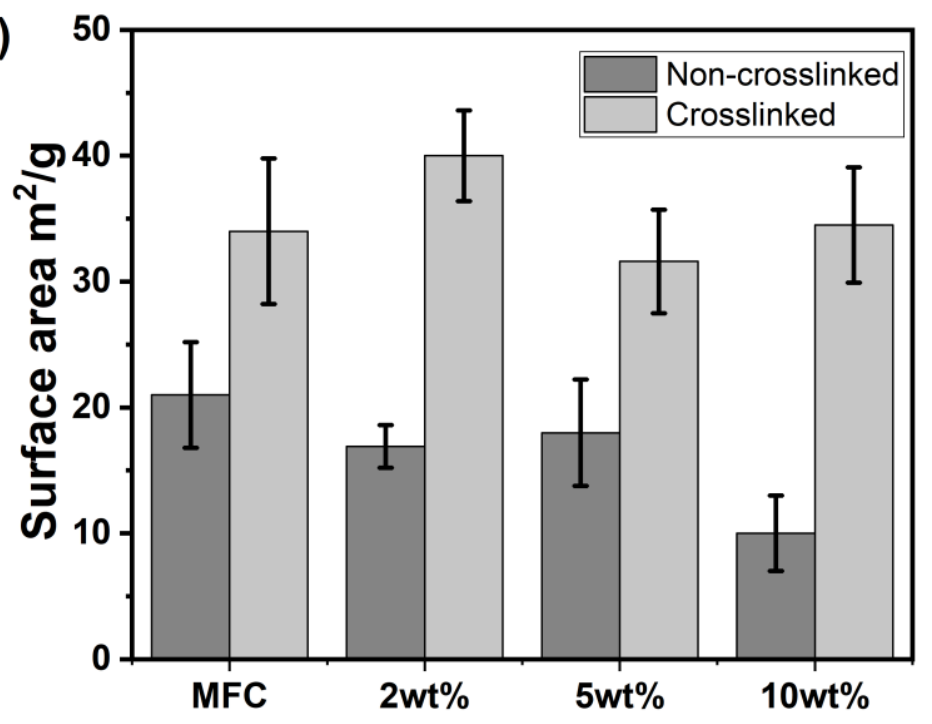

(b)

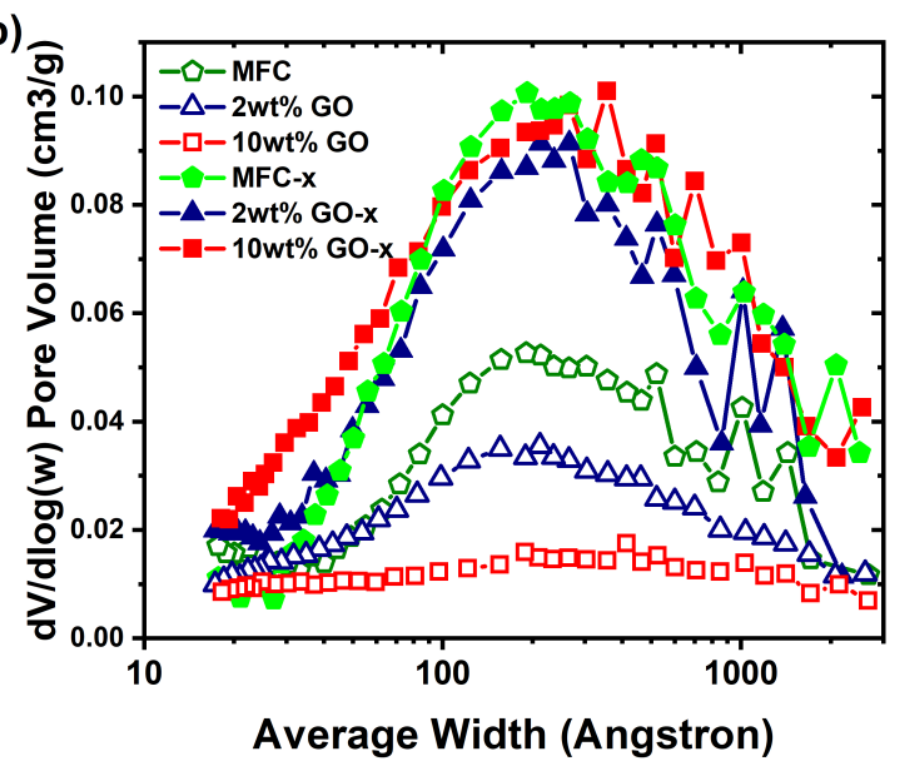

Figure 3.4 (a) Specific surface area of Non-crosslinked and Crosslinked MFC/GO mats; (b) Pore size distribution analyzed by BJH method of Non-crosslinked MFC/GO mat ( $2 \mathrm{wt} \% \mathrm{GO}$, $10 \mathrm{wt} \% \mathrm{GO}$ ), Crosslinked MFC/GO mat (2wt\%-x, 10wt \%-x), Non-crosslinked and Crosslinked MFC mat are shown for comparison 

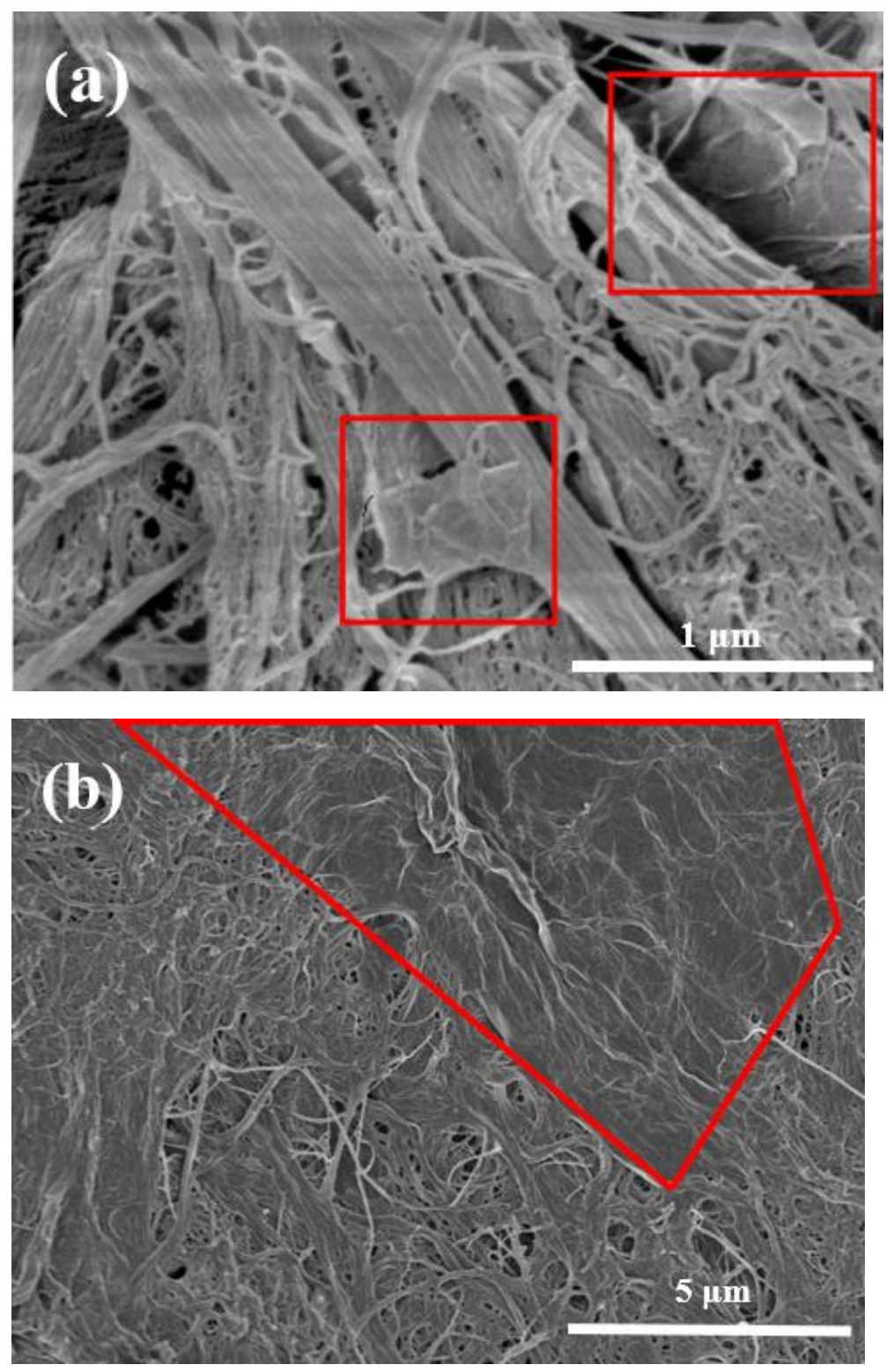

Figure 3.5 (a) SEM image of crosslinked 2wt $\%$-GO/MFC mat (b) SEM image of noncrosslinked GO/MFC mat 


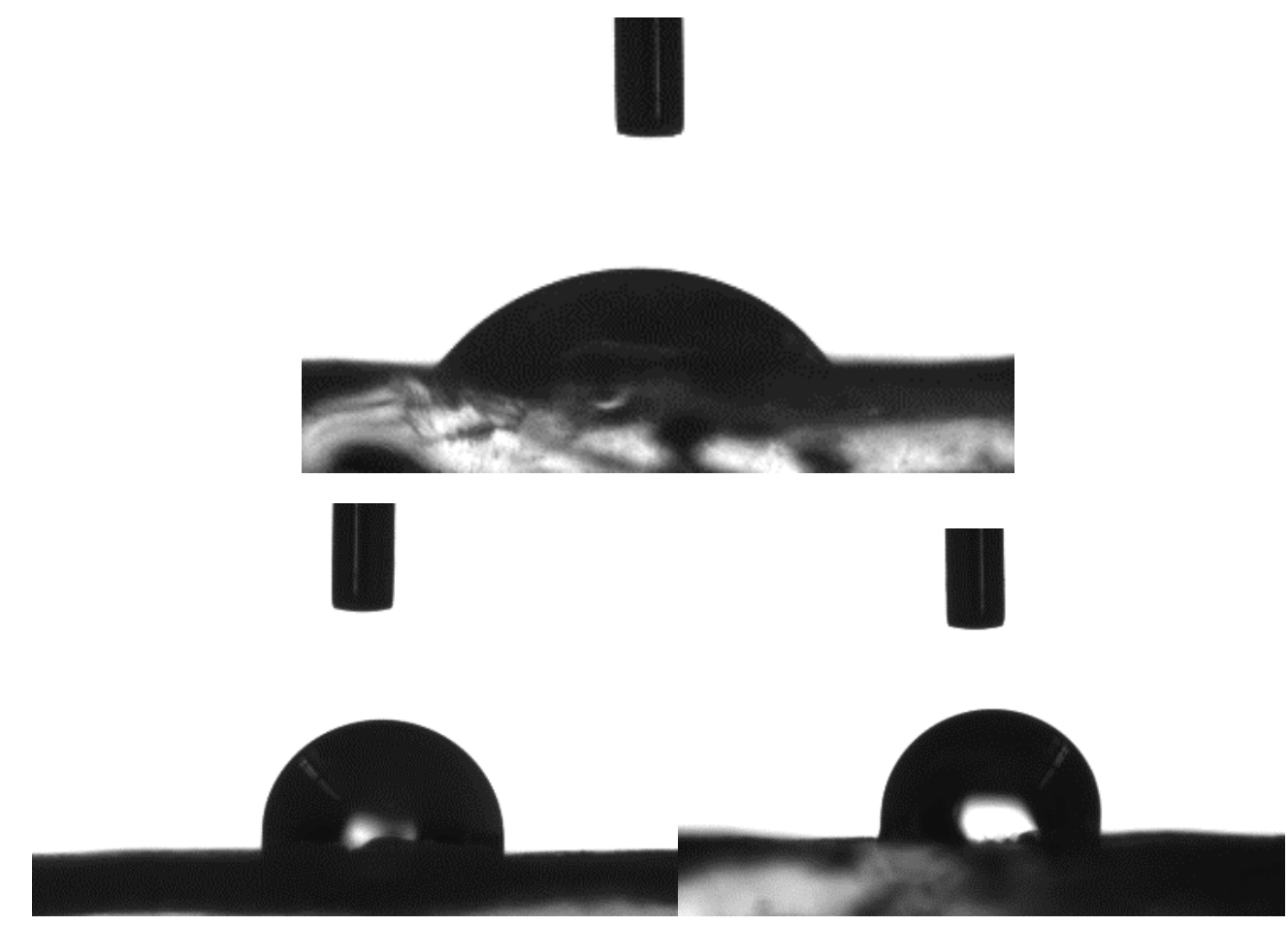

Figure 3.6 Water contact angle of neat MFC (top), crosslinked MFC (bottom left), crosslinked 2wt\%-GO/MFC (bottom right) 


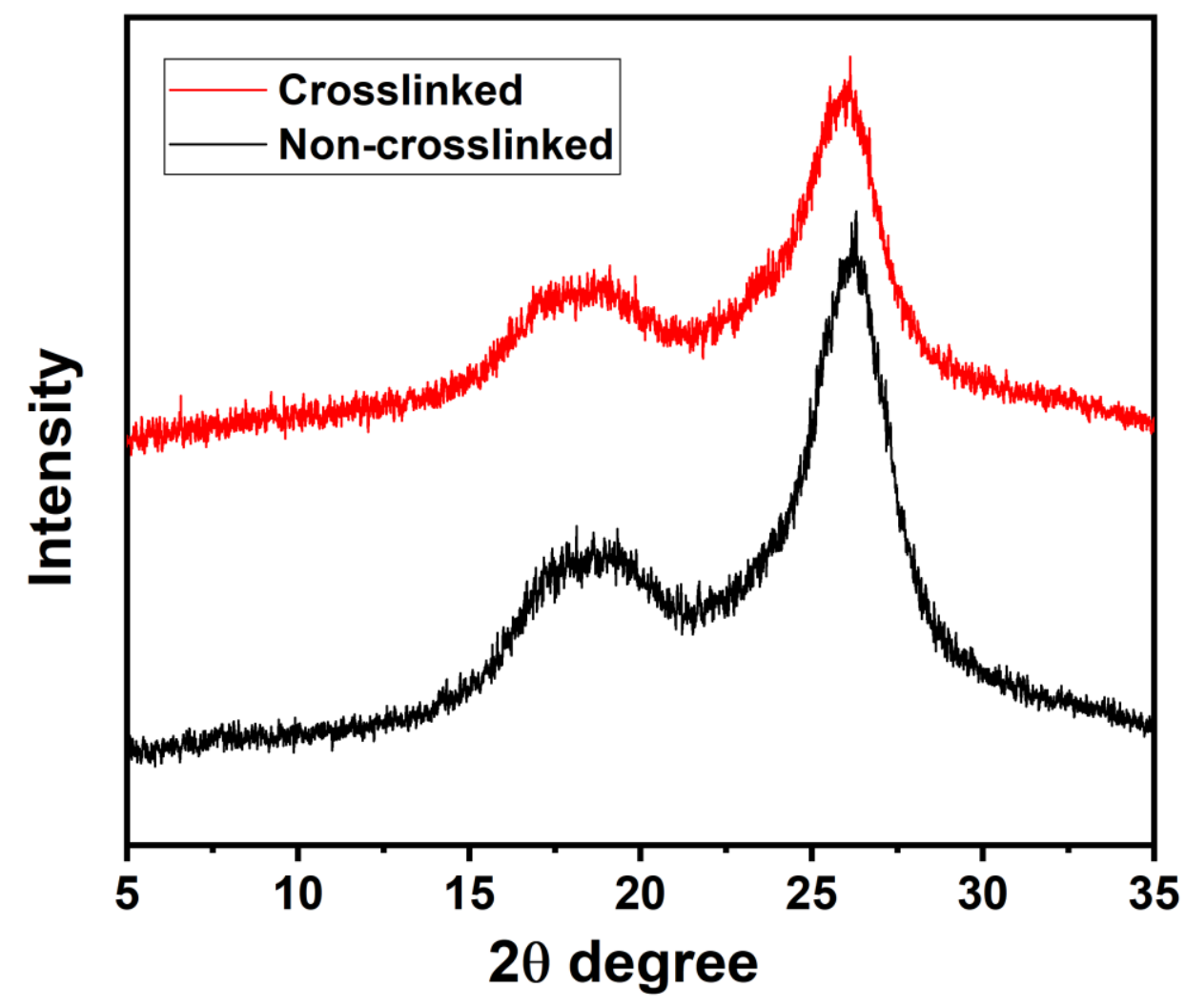

Figure 3.7 XRD for Non-crosslinked MFC and Crosslinked MFC mat 


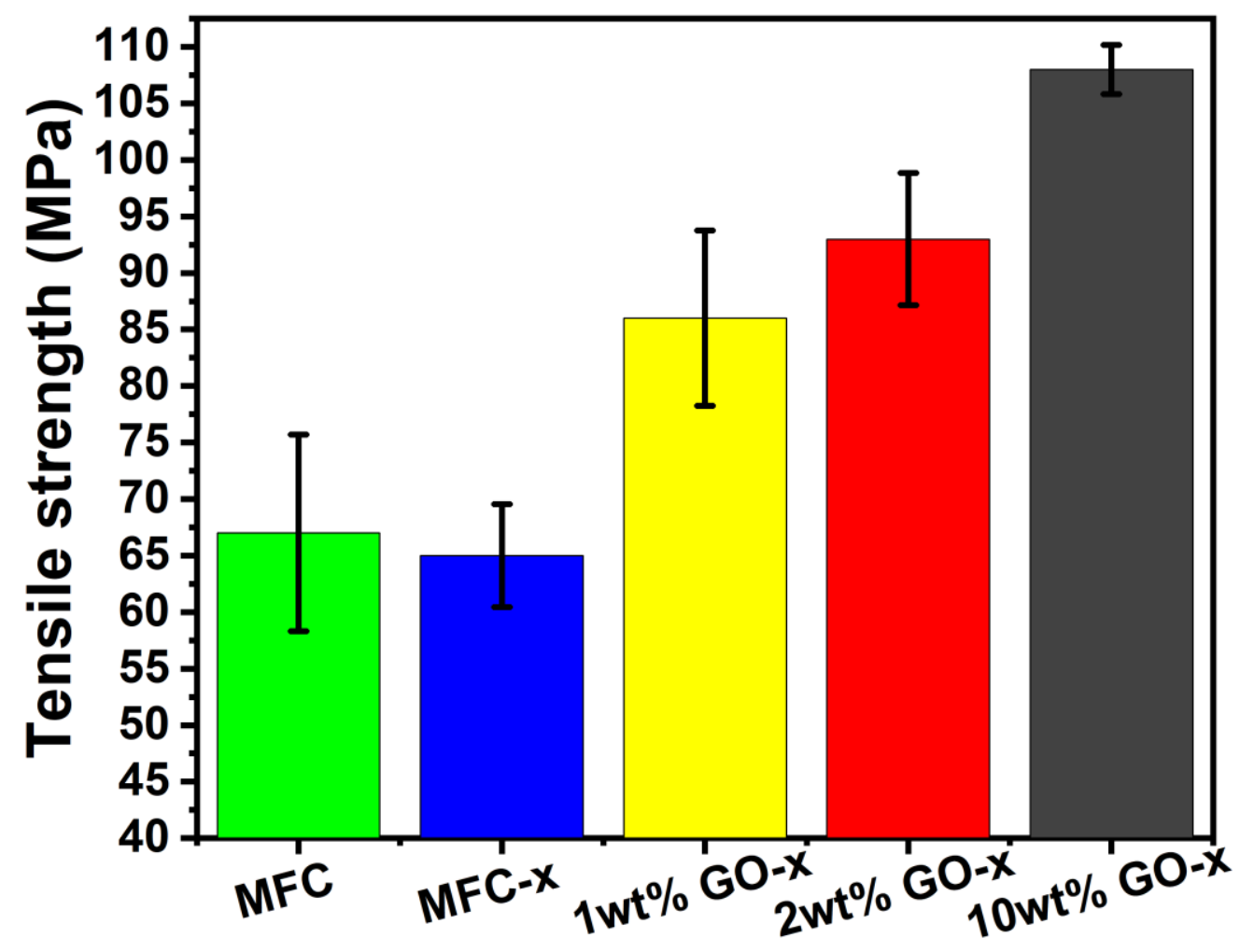

Figure 3.8 Tensile test for Non-crosslinked MFC film (MFC), crosslinked MFC film (MFC-x) and crosslinked MFC/GO film with $1 \mathrm{wt} \%$, 2wt $\%$, 10wt $\%$ GO loading 


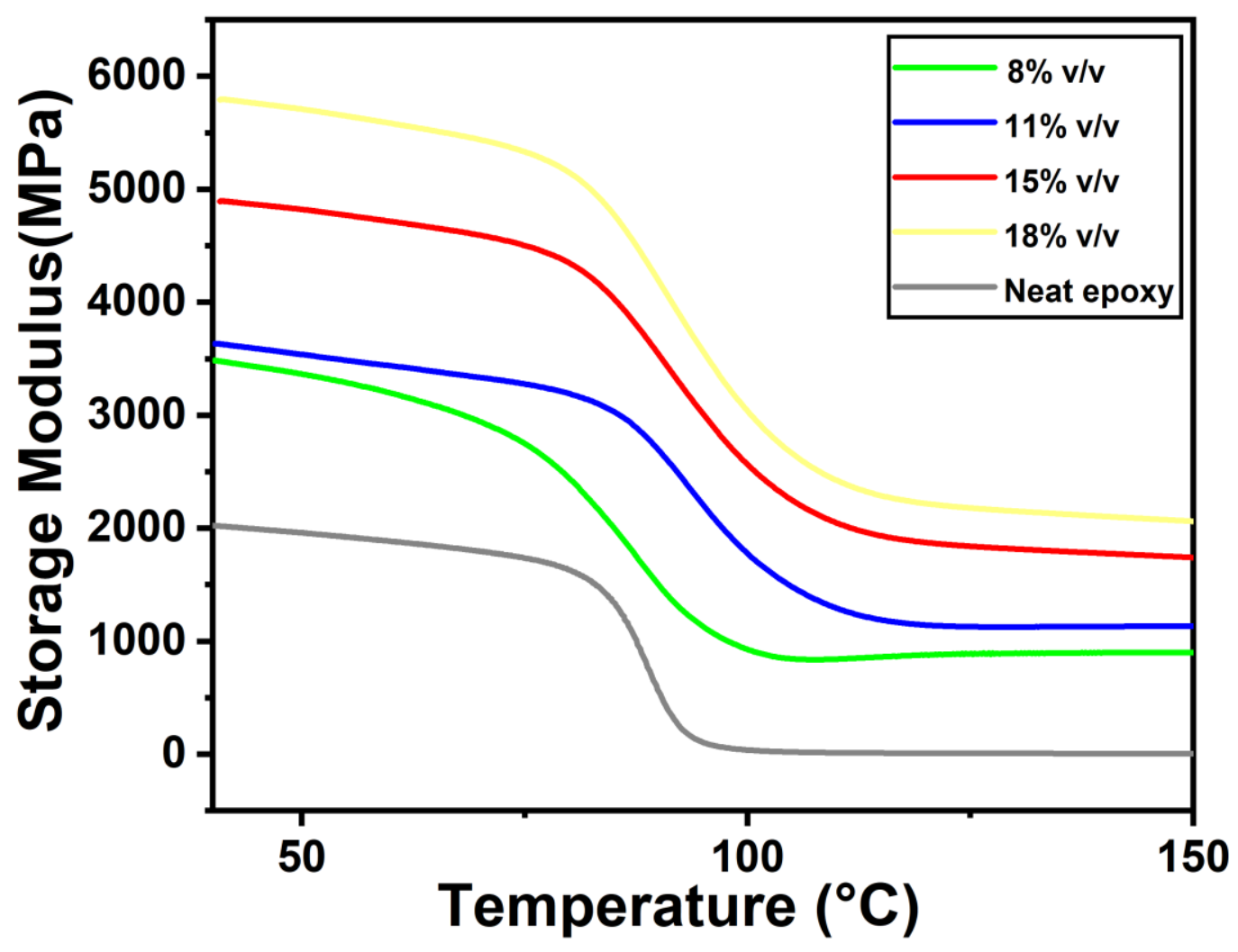

Figure 3.9 Storage modulus of non-crosslinked MFC/epoxy composites 

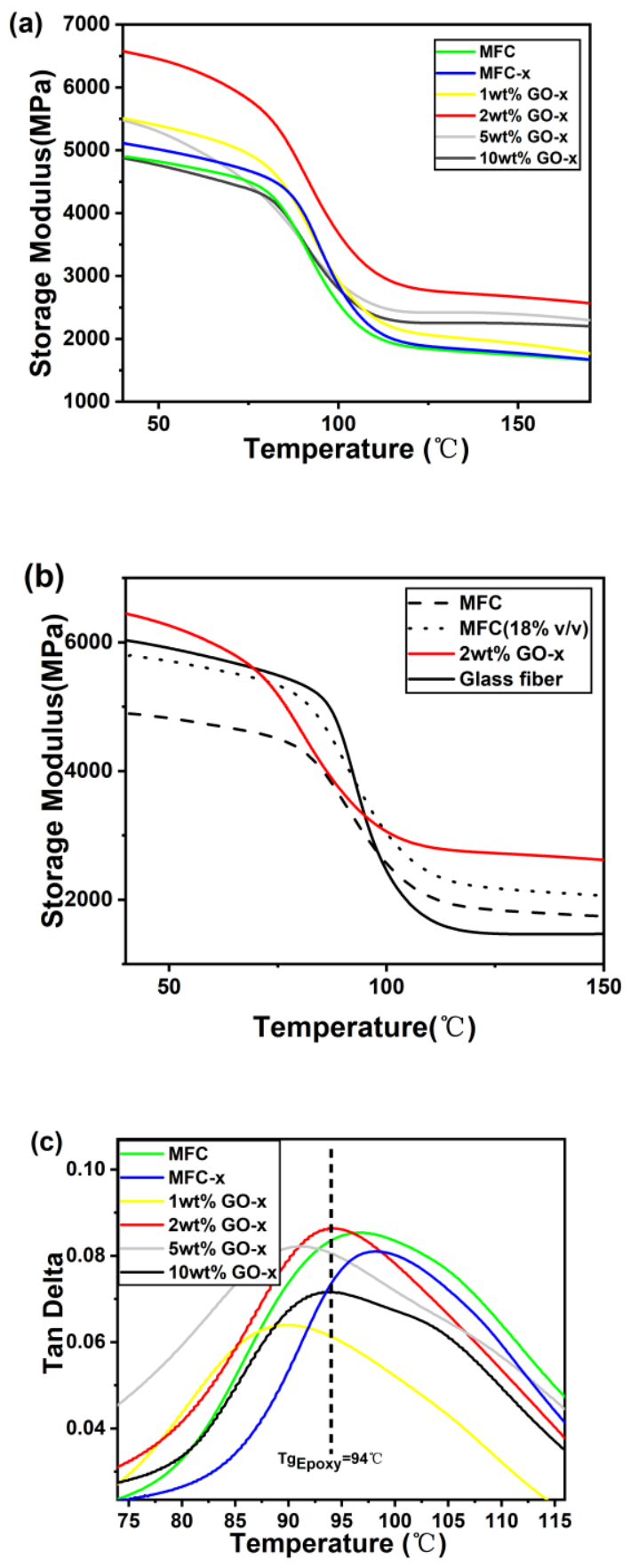

Figure 3.10 (a) Storage Modulus for crosslinked MFC/GO epoxy composites (b) Storage modulus comparison between MFC/epoxy, Glass fiber/epoxy and crosslinked $2 \mathrm{wt} \% \mathrm{GO} / \mathrm{MFC}$ composites, (c) Glass transition temperature for crosslinked MFC/epoxy composites. All the composites have a fiber content of 15 vol. \% unless specifically labeled 


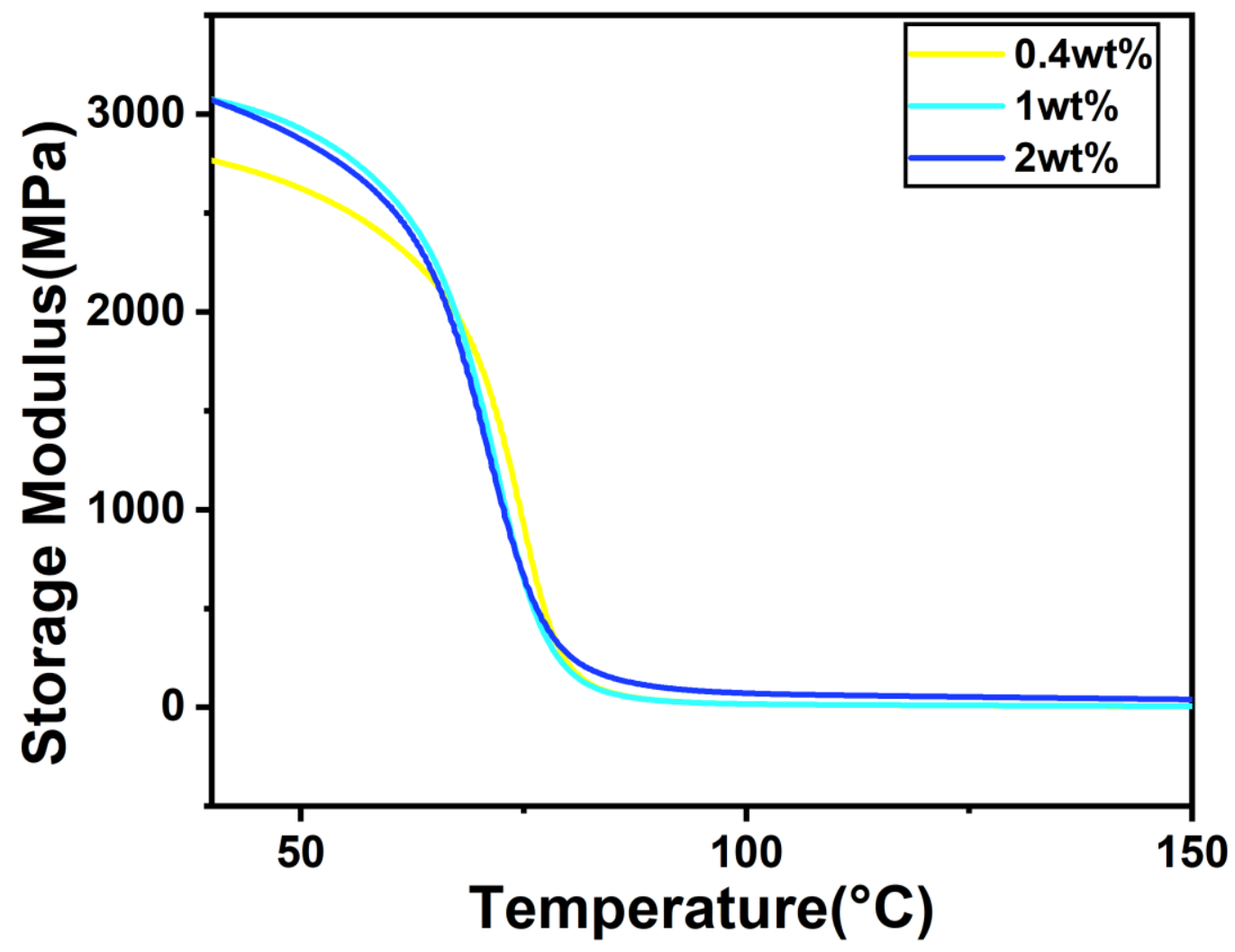

Figure 3.11 Storage modulus of GO/MFC epoxy comopsites with 0.4 wt. $\%, 1$ wt. $\%$ and 2 wt. \% GO. 

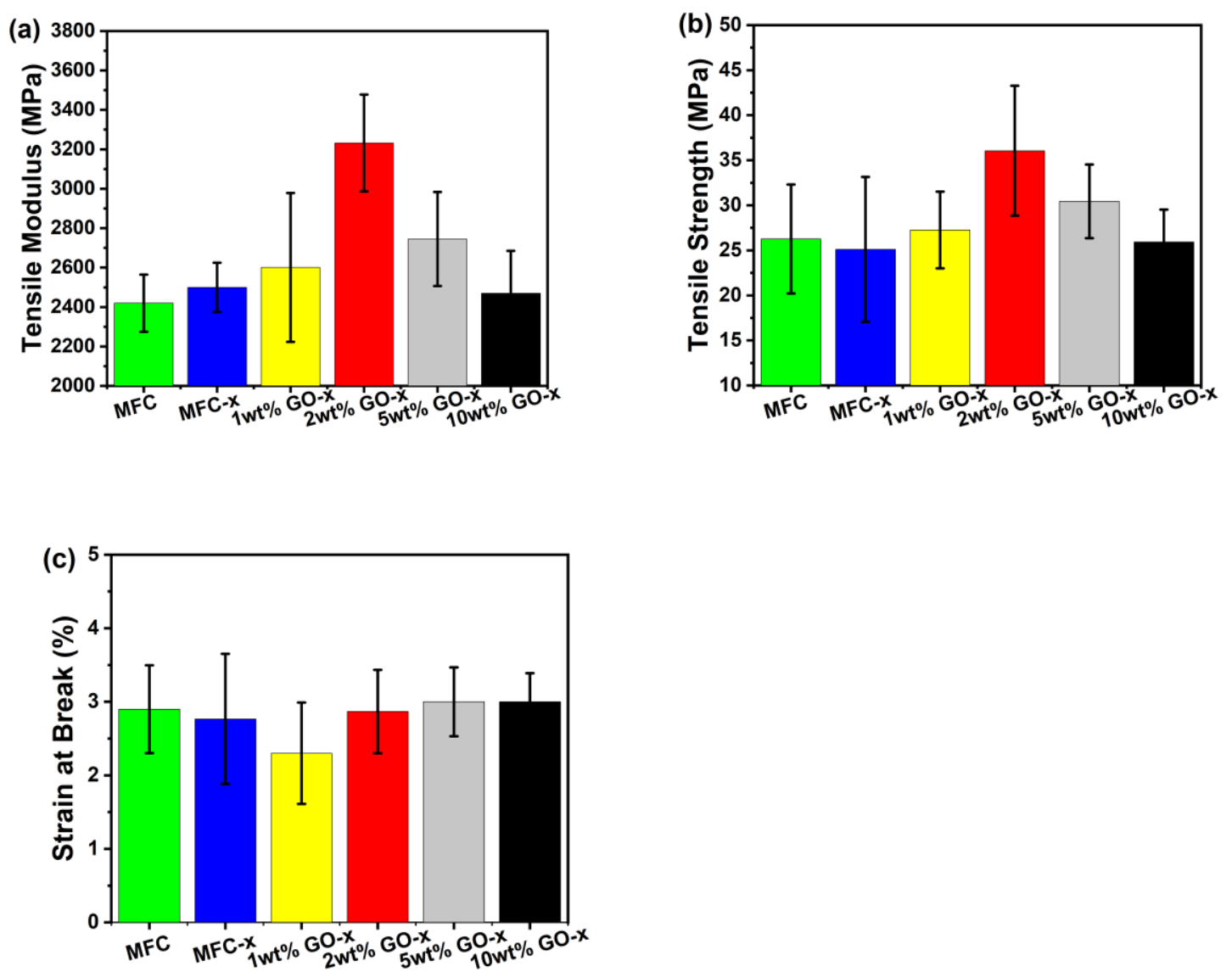

Figure 3.12 (a) Tensile modulus of epoxy composites with 15 vol \% MFC, (b) Tensile Strength, (c) Stain at break 


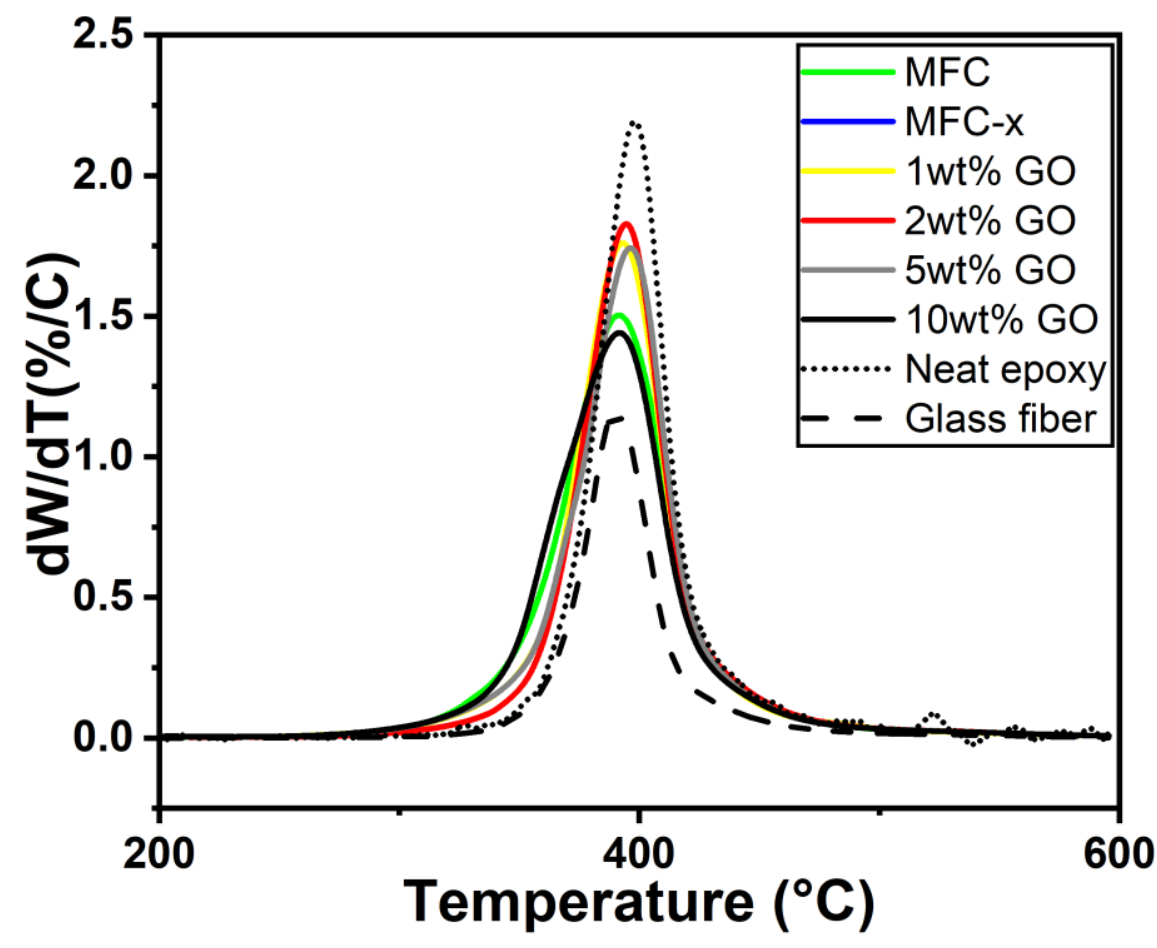

Figure 3.13 Thermal degradation peak for neat epoxy, glass fiber /epoxy, MFC/epoxy and MFC/GO epoxy composites consists of 15 vol. \% MFC with different amounts of GO crosslinking in wt.\% 


\section{Chapter 4}

\section{Conclusion and future works}

\subsection{Conclusion}

Neat MFC can be used as an alternative reinforcement in epoxy composites. Epoxy composites were prepared by impregnation of freeze-dried porous mats with the epoxy resin. The storage modulus of MFC/epoxy composites gradually increase with the increasing fiber content, while glass fibers remain superior at the same volume content in the composites. The poor fiber dispersion and weak interfacial adhesion are considered the main reasons which restrict the reinforcing effect of MFC in epoxy composites.

GO and MFC both contains a large amount of hydroxyl groups. By using ECH as crosslinker, MFC was successfully crosslinked with GO. GO was reduced during the reaction. The hydrophobization of MFC/GO after crosslinking was confirmed by the water contact angle, which may benefit the epoxy infusion and improve the interfacial adhesion.

The BET surface area and BJH pore size distribution analysis demonstrated that aggregation of MFC fibers was prevented by crosslinking. The specific surface area and mesoporosity of crosslinked mats is much higher as compared with non-crosslinked mats. The crystalline structure as observed via XRD was preserved during the crosslinking reaction though the crystallinity decreased slightly. Via GO crosslinking, better dispersion of MFC fibers, better 
interfacial adhesion between reinforcement and epoxy matrix and strengthened MFC fiber network could be realized in a solvent-free way.

The mechanical properties of crosslinked $2 \mathrm{wt} \%$ GO/MFC epoxy composites reached the highest among the composites with 15 vol. \% MFC. At higher GO loadings, the properties of composites decreased due to the agglomeration of GO sheets. The crosslinked MFC/GO 、 FC can exceed that of the glass fibers at similar fiber volume content.

\subsection{Future work}

The petroleum based epoxy resin, DGEBA, could be replaced with bio-based epoxy resin to further increase the sustainability. Functionalization of MFC and GO can be studied to further improve the interfacial adhesion and induce new crosslinking mechanism to improve the crosslinking efficiency and prevent the agglomeration of graphene oxide sheets. After that, thermal and electrical conductivity of crosslinked MFC/GO epoxy composites at high GO loading may be investigated. Other functionalized carbon materials may be used to crosslink with MFC to prepare epoxy composites with high strength and new applications. 


\section{References}

1. Jin, F.-L., Li, X. \& Park, S.-J. Synthesis and application of epoxy resins: A review. J. Ind. Eng. Chem. 29, 1-11 (2015).

2. De Nograro, F. F., Guerrero, P., Corcuera, M. A. \& Mondragon, I. Effects of chemical structure of hardener on curing evolution and on the dynamic mechanical behavior of epoxy resins. J. Appl. Polym. Sci. 56, 177-192 (1995).

3. Choi, Y.-K. et al. Mechanical and physical properties of epoxy composites reinforced by vapor grown carbon nanofibers. Carbon N. Y. 43, 2199-2208 (2005).

4. Hameed, N., Sreekumar, P. A., Francis, B., Yang, W. \& Thomas, S. Morphology, dynamic mechanical and thermal studies on poly(styrene-co-acrylonitrile) modified epoxy resin/glass fibre composites. Compos. Part A Appl. Sci. Manuf. 38, 2422-2432 (2007).

5. Ansari, F., Galland, S., Johansson, M., Plummer, C. J. G. \& Berglund, L. A. Cellulose nanofiber network for moisture stable, strong and ductile biocomposites and increased epoxy curing rate. Compos. Part A Appl. Sci. Manuf. 63, 35-44 (2014).

6. Yue, L. et al. High Performance Biobased Epoxy Nanocomposite Reinforced with a Bacterial Cellulose Nanofiber Network. ACS Sustain. Chem. Eng. 7, 5986-5992 (2019).

7. Xu, S., Girouard, N., Schueneman, G., Shofner, M. L. \& Meredith, J. C. Mechanical and thermal properties of waterborne epoxy composites containing cellulose nanocrystals. Polymer (Guildf). 54, 6589-6598 (2013).

8. Yue, L. et al. Surface-modified cellulose nanocrystals for biobased epoxy nanocomposites. Polymer (Guildf). 134, 155-162 (2018). 
9. Wu, G. et al. Thermoset nanocomposites from waterborne bio-based epoxy resin and cellulose nanowhiskers. Carbohydr. Polym. 127, 229-235 (2015).

10. Emami, Z., Meng, Q., Pircheraghi, G. \& Manas-Zloczower, I. Use of surfactants in cellulose nanowhisker/epoxy nanocomposites: effect on filler dispersion and system properties. Cellulose 22, 3161-3176 (2015).

11. Dwivedi, U. K. \& Chand, N. Influence of wood flour loading on tribological behavior of epoxy composites. Polym. Compos. 29, 1189-1192 (2008).

12. Shibata, M., Teramoto, N., Takada, Y.\& Yoshihara, S. Preparation and properties of biocomposites composed of glycerol-based epoxy resins, tannic acid, and wood flour. $J$. Appl. Polym. Sci. 118, 2998-3004 (2010).

13. Boopalan, M., Niranjanaa, M. \& Umapathy, M. J. Study on the mechanical properties and thermal properties of jute and banana fiber reinforced epoxy hybrid composites. Compos. Part B Eng. 51, 54-57 (2013).

14. Rong, M. Z., Zhang, M. Q., Liu, Y., Yang, G. C. \& Zeng, H. M. The effect of fiber treatment on the mechanical properties of unidirectional sisal-reinforced epoxy composites. Compos. Sci. Technol. 61, 1437-1447 (2001).

15. Lamy, B. \& Baley, C. Stiffness prediction of flax fibers-epoxy composite materials. $J$. Mater. Sci. Lett. 19, 979-980 (2000).

16. Mishra, V. \& Biswas, S. Physical and Mechanical Properties of Bi-directional Jute Fiber Epoxy Composites. Procedia Eng. 51, 561-566 (2013).

17. Islam, M. S., Pickering, K. L. \& Foreman, N. J. Influence of alkali fiber treatment and fiber processing on the mechanical properties of hemp/epoxy composites. J. Appl. Polym. Sci. 119, 3696-3707 (2011). 
18. Gassan, J. \& Bledzki, A. K. Alkali treatment of jute fibers: Relationship between structure and mechanical properties. J. Appl. Polym. Sci. 71, 623-629 (1999).

19. Zimmermann, T., Bordeanu, N. \& Strub, E. Properties of nanofibrillated cellulose from different raw materials and its reinforcement potential. Carbohydr. Polym. 79, 10861093 (2010).

20. Tibolla, H., Pelissari, F. M. \& Menegalli, F. C. Cellulose nanofibers produced from banana peel by chemical and enzymatic treatment. LWT - Food Sci. Technol. 59, 13111318 (2014).

21. Pelissari, F. M., Sobral, P. J. do A. \& Menegalli, F. C. Isolation and characterization of cellulose nanofibers from banana peels. Cellulose 21, 417-432 (2014).

22. Iguchi, M., Yamanaka, S. \& Budhiono, A. Bacterial cellulose - a masterpiece of nature's arts. J. Mater. Sci. 35, 261-270 (2000).

23. Siró, I. \& Plackett, D. Microfibrillated cellulose and new nanocomposite materials: a review. Cellulose 17, 459-494 (2010).

24. Lu, J., Askeland, P. \& Drzal, L. T. Surface modification of microfibrillated cellulose for epoxy composite applications. Polymer (Guildf). 49, 1285-1296 (2008).

25. Hsieh, J.-T., Wang, M.-J., Lai, J.-T. \& Liu, H.-S. A novel static cultivation of bacterial cellulose production by intermittent feeding strategy. J. Taiwan Inst. Chem. Eng. 63, 4651 (2016).

26. Iwamoto, S., Kai, W., Isogai, A. \& Iwata, T. Elastic Modulus of Single Cellulose Microfibrils from Tunicate Measured by Atomic Force Microscopy. Biomacromolecules 10, 2571-2576 (2009).

27. Cosgrove, D. J. Growth of the plant cell wall. Nat. Rev. Mol. Cell Biol. 6, 850 (2005). 
28. Cheng, G., Zhang, X., Simmons, B. \& Singh, S. Theory, practice and prospects of X-ray and neutron scattering for lignocellulosic biomass characterization: towards understanding biomass pretreatment. Energy Environ. Sci. 8, 436-455 (2015).

29. Abdul Khalil, H. P. S., Bhat, A. H. \& Ireana Yusra, A. F. Green composites from sustainable cellulose nanofibrils: A review. Carbohydr. Polym. 87, 963-979 (2012).

30. Jonoobi, M. et al. Different preparation methods and properties of nanostructured cellulose from various natural resources and residues: a review. Cellulose 22, 935-969 (2015).

31. Chen, W. et al. Individualization of cellulose nanofibers from wood using high-intensity ultrasonication combined with chemical pretreatments. Carbohydr. Polym. 83, 1804$1811(2011)$.

32. Zuluaga, R. et al. Cellulose microfibrils from banana rachis: Effect of alkaline treatments on structural and morphological features. Carbohydr. Polym. 76, 51-59 (2009).

33. Saito, T., Kimura, S., Nishiyama, Y. \& Isogai, A. Cellulose Nanofibers Prepared by TEMPO-Mediated Oxidation of Native Cellulose. Biomacromolecules 8, 2485-2491 (2007).

34. Iwamoto, S., Lee, S.-H. \& Endo, T. Relationship between aspect ratio and suspension viscosity of wood cellulose nanofibers. Polym. J. 46, 73 (2013).

35. Henriksson, M., Henriksson, G., Berglund, L. A. \& Lindström, T. An environmentally friendly method for enzyme-assisted preparation of microfibrillated cellulose (MFC) nanofibers. Eur. Polym. J. 43, 3434-3441 (2007). 
36. Habibi, Y., Lucia, L. A. \& Rojas, O. J. Cellulose Nanocrystals: Chemistry, SelfAssembly, and Applications. Chem. Rev. 110, 3479-3500 (2010).

37. Fernandes, A. N. et al. Nanostructure of cellulose microfibrils in spruce wood. Proc. Natl. Acad. Sci. 108, E1195 LP-E1203 (2011).

38. Nishiyama, Y. Structure and properties of the cellulose microfibril. J. Wood Sci. 55, 241-249 (2009).

39. Isogai, A., Saito, T. \& Fukuzumi, H. TEMPO-oxidized cellulose nanofibers. Nanoscale 3, 71-85 (2011).

40. Pasquini, D., Teixeira, E. de M., Curvelo, A. A. da S., Belgacem, M. N. \& Dufresne, A. Surface esterification of cellulose fibres: Processing and characterisation of low-density polyethylene/cellulose fibres composites. Compos. Sci. Technol. 68, 193-201 (2008).

41. Abdelmouleh, M., Boufi, S., Belgacem, M. N., Dufresne, A. \& Gandini, A. Modification of cellulose fibers with functionalized silanes: Effect of the fiber treatment on the mechanical performances of cellulose-thermoset composites. J. Appl. Polym. Sci. 98, 974-984 (2005).

42. Stenstad, P., Andresen, M., Tanem, B. S. \& Stenius, P. Chemical surface modifications of microfibrillated cellulose. Cellulose 15, 35-45 (2008).

43. Dreyer, D. R., Park, S., Bielawski, C. W. \& Ruoff, R. S. The chemistry of graphene oxide. Chem. Soc. Rev. 39, 228-240 (2010).

44. Hummers, W. S. \& Offeman, R. E. Preparation of Graphitic Oxide. J. Am. Chem. Soc. 80, 1339 (1958). 
45. Azizi Samir, M. A. S., Alloin, F. \& Dufresne, A. Review of Recent Research into Cellulosic Whiskers, Their Properties and Their Application in Nanocomposite Field. Biomacromolecules 6, 612-626 (2005).

46. Lerf, A., He, H., Forster, M. \& Klinowski, J. Structure of Graphite Oxide Revisited. J. Phys. Chem. B 102, 4477-4482 (1998).

47. Kim, C. H., Youn, H. J. \& Lee, H. L. Preparation of cross-linked cellulose nanofibril aerogel with water absorbency and shape recovery. Cellulose 22, 3715-3724 (2015).

48. Wan Ngah, W. S., Hanafiah, M. A. K. M. \& Yong, S. S. Adsorption of humic acid from aqueous solutions on crosslinked chitosan-epichlorohydrin beads: Kinetics and isotherm studies. Colloids Surfaces B Biointerfaces 65, 18-24 (2008).

49. Fan, X. et al. Deoxygenation of Exfoliated Graphite Oxide under Alkaline Conditions: A Green Route to Graphene Preparation. Adv. Mater. 20, 4490-4493 (2008).

50. Liu, X. Y., Timar, M. C., Varodi, A. M. \& Sawyer, G. An investigation of accelerated temperature-induced ageing of four wood species: colour and FTIR. Wood Sci. Technol. 51, 357-378 (2017).

51. Gao, K. et al. Cellulose nanofiber-graphene all solid-state flexible supercapacitors. J. Mater. Chem. A 1, 63-67 (2013).

52. Gao, K. et al. Cellulose nanofibers/multi-walled carbon nanotube nanohybrid aerogel for all-solid-state flexible supercapacitors. RSC Adv. 3, 15058-15064 (2013).

53. Zhu, Y. et al. Graphene and Graphene Oxide: Synthesis, Properties, and Applications. Adv. Mater. 22, 3906-3924 (2010). 
54. Guo, B., Chen, W. \& Yan, L. Preparation of Flexible, Highly Transparent, Cross-Linked Cellulose Thin Film with High Mechanical Strength and Low Coefficient of Thermal Expansion. ACS Sustain. Chem. Eng. 1, 1474-1479 (2013).

55. Saba, N. et al. Mechanical, morphological and structural properties of cellulose nanofibers reinforced epoxy composites. Int. J. Biol. Macromol. 97, 190-200 (2017).

56. Johar, N., Ahmad, I. \& Dufresne, A. Extraction, preparation and characterization of cellulose fibres and nanocrystals from rice husk. Ind. Crops Prod. 37, 93-99 (2012).

57. Segal, L., Creely, J. J., Martin, A. E. \& Conrad, C. M. An Empirical Method for Estimating the Degree of Crystallinity of Native Cellulose Using the X-Ray Diffractometer. Text. Res. J. 29, 786-794 (1959).

58. Almasi, H., Ghanbarzadeh, B., Dehghannya, J., Entezami, A. A. \& Asl, A. K. Novel nanocomposites based on fatty acid modified cellulose nanofibers/poly(lactic acid): Morphological and physical properties. Food Packag. Shelf Life 5, 21-31 (2015).

59. Freire, C. S. R., Silvestre, A. J. D., Neto, C. P., Belgacem, M. N. \& Gandini, A. Controlled heterogeneous modification of cellulose fibers with fatty acids: Effect of reaction conditions on the extent of esterification and fiber properties. J. Appl. Polym. Sci. 100, 1093-1102 (2006).

60. Jandura, P., Kokta, B. V \& Riedl, B. Fibrous long-chain organic acid cellulose esters and their characterization by diffuse reflectance FTIR spectroscopy, solid-state CP/MAS 13C-NMR, and X-ray diffraction. J. Appl. Polym. Sci. 78, 1354-1365 (2000).

61. Abraham, E. et al. Highly Modified Cellulose Nanocrystals and Formation of EpoxyNanocrystalline Cellulose (CNC) Nanocomposites. ACS Appl. Mater. Interfaces 8 , 28086-28095 (2016). 
62. Liu, L., Zhang, J., Zhao, J. \& Liu, F. Mechanical properties of graphene oxides. Nanoscale 4, 5910-5916 (2012).

63. Bao, C. et al. In situ preparation of functionalized graphene oxide/epoxy nanocomposites with effective reinforcements. J. Mater. Chem. 21, 13290-13298 (2011). 